\title{
O ENSINO E A PRÁTICA DA ENFERMAGEM EM RELAÇÂO AO PROGRAMA DE CONTROLE DA TUBERCULOSE NO ESTADO DO RIO DE JANEIRO *
}

\author{
Ieda Barreira e Castro ** \\ Jurema Cunha dos Santos ** \\ Maria Alice Rodrigues de Lima** \\ Maria Nazarena Campos Figueira**
}

ReBEn/05

CASTRO, I.B. e Colaboradores - O ensino e a prática da enfermagem em relação ao programa de controle da tuberculose no Estado do Rio de Janeiro. Rev. Bras. Enf.; DF, 33 : 318-355, 1980.

\section{O PROBLEMA}

Castro (1976) ao estudar o problema da formação de profissionais de enfermagem, no que se refere à sua adequação aos programas de controle da tuberculose, lembra que:

"A enfermagem brasileira, desde os seus primórdios, vem contribuindo marcadamente para os objetivos da luta contra a tuberculose no país. Nos últimos vinte anos, a estratégia desta luta sofreu mudanças radicais, devidas ao progresso científico e tecnológico, à aplicação de uma metodologia econômica ao planejamento de saúde e a uma crescente interação intersetorial, a todos os níveis. Os programas de controle da tuberculose, cada vez mais, são desenvol- vidos por equipes não especializadas, em serviços gerais de saúde, o que implica na possibilidade de utilização de recursos humanos recém-formados".

Naquele estudo, foram questionados escolas e cursos de enfermagem e as secretarias estaduais de saúde, ficou demonstrado que existe um círculo vicioso no processo de formação e utilização dos profissionais de enfermagem: "os cursos de enfermagem não estão orientados de modo a preparar profissionais capazes de atuar imediatamente em programas de controle da tuberculose integrados nos serviços gerais de saúde; ao mesmo tempo, esses serviços não estão proporcionando aos estudantes modelos adequados de desempenho".

* Tema livre apresentado no XXXI CBEn - Ceará, 1979.

** Enfermeiras da Divisão Nacional de Pneumologia Sanitária - Secretaria Nacional de Programas Especiais de Saúde - M.S. 
CASTRO, I.B. e Colaboradores - O ensino e a prática da enfermagem em relação ao programa de controle da tuberculose no Estado do Rio de Janeiro. Rev. Bras. Enf.; DF, 33 : 318-355, 1980.

No presente estudo, cujos dados foram colhidos em seqüência aos daquele anteriormente citado, e que o complementa, questiona-se de acordo com recomendação do "citado trabalho", as professoras de enfermagem e as enfermeiras dos centros de saúde que servem de campo de estágio às escolas de enfermagem do Estado do Rio de Janeiro, quanto à sua participação no programa de controle da tuberculose e à sua opinião sobre algumas questões emergentes a ele relacionados. Patrocinou a pesquisa a Divisão Nacional de Pneumologia Sanitária.

\section{OBJETIVOS}

1 - Caracterizar a população objeto do estudo: professoras de escolas de enfermagem e enfermeiras que trabalham em centros de saúde que lhes servem como campo de estágio (onde e quando se formaram).

2 - Descrever seu preparo e experiências profissionais, no que tange ao controle da tuberculose e ao ensino de estudantes de enfermagem, no que se refere à tuberculose.

3 - Comparar as opiniões e atitudes dessas enfermeiras com as normas propostas pela Divisão Nacional de Pneumologia Sanitária (DNPS) do Ministério da Saúde e com a tendência de integração das atividades de controle da tuberculose nos serviços gerais de saúde.

4 - Comparar as expectativas dos dois grupos quanto às capacidades consideradas imprescindíveis a uma enfermeira recém-formada para atuar em um programa de controle da tuberculose.

5 - Comparar aquelas capacidades com as atividades de controle da tuberculose desenvolvidas pelos estudantes de enfermagem e com as modificações julgadas necessárias no preparo dos alunos, em relação à tuberculose.
6 - Situar a consulta de enfermagem, quanto ao nível do executante.

\section{METODOLOGIA}

1 - A população-alvo é a totalidade das professoras das Escolas de Enfermagem do Rio de Janeiro e das Enfermeiras dos Centros de Saúde que lhes servem de campo de estágio, a saber:

Escolas de Enfermagem:

- Escola de Enfermagem Ana Neri da Universidade Federal do Rio de Janeiro/UFRJ.

- Escola de Enfermagem da Universidade Federal Fluminense Niterói - RJ/UFF.

- Escola de Enfermagem da Universidade Estadual do Rio de Janeiro/UERJ.

- Faculdade de Enfermagem da Federação das Escolas Federais Isoladas do Rio de Janeiro/FEFIERJ.

- Centros de Saúde:

- Centros Municipais de Saúde (CMS) das Regiões Administrativas (RA) do Rio de Janeiro:

CMS Maria A. Estrela - IX RA. CMS Marcolino Candau - III RA. CMS Manoel José Ferreira - IV RA.

CMS Barros Barreto - V RA. CMS Heitor Beltrão - VIII RA. CMS Ernesto Zeferino Tibau Jr. - VII RA.

- Unidade Escola de Saúde Pública Geraldo de Paula ミouza - Rio.

- Unidade Sanitária Germano Sinval Faria - Escola Nacional de Saúde Pública - Rio.

- Centro de Saúde Carlos Antonio da Silva - Niterói.

- Centro de Saúde Miguel Couto Filho - Niterói. 
CASTRO, I.B. e Colaboradores - O ensino e a prática da enfermagem em relação ao programa de controle da tuberculose no Estado do Rio de Janeiro. Rev. Bras. En?.; DF, 33 : 318-355, 1980.

2 - A coleta de dados foi efetuada por algumas das autoras e com a colaboração de colegas da DNPS, mediante a aplicação de questionário (modelo em anexo), entregues e recolhidos pessoalmente. A apuração dos dados foi manual.

\section{RESULTADOS}

Caracterização geral da população estudada:

Das 137 enfermeiras lotadas nas Escolas de Enfermagem, 127 encontravamse em atividade, das quais $99(78,0 \%)$ responderam ao questionário. Já nos centros de saúde estavam lotadas 123 enfermeiras e, das 93 em serviço, 77 $(82,8 \%)$ responderam ao questionário. Assim, dos 176 respondentes, 56,3\% (99) trabalhavam em escolas de enfermagem e $43,7 \%$ (77) em centros de saúde.

As 99 respondentes que trabalham em escolas de enfermagem são procedentes de 20 Escolas, que estão distribuídas nas cinco regiões do país. Entretanto, $86(87,0 \%)$ graduaram-se em escolas sediadas no Sudeste do país e dessas $77(77,8 \%)$ no Estado do Rio de Janeiro, sendo que $37(37,3 \%)$ concluíram o curso na Escola Ana Neri e 23 $(23,2 \%)$ na Escola de Enfermagem da UFF.

Das 77 enfermeiras que trabalhavam em centros de saúde, $75 \quad(97,4 \%)$ graduaram-se na região Sudeste, sendo que $68(88,3 \%)$ no Estado do Rio de Janeiro, prevalecendo os contingentes oriundos da Escola Ana Neri e da Escola de Enfermagem da UFF com 19 $(24,6 \%)$ e $15(19,4 \%)$, respectivamente.

Assim, no cômputo global dos 176 respondentes, $161(91,4 \%)$ graduaramse no Sudeste, sendo que dessas 145 $(82,3 \%)$ graduaram-se no Estado do Rio. A Escola Ana Neri formou maior número, $56(31,8 \%)$ seguindo-se a Escola de Enfermagem da UFF com o to- tal de $38(21,6 \%)$ e a Escola de Enfermagem da UERJ, com $24(13,6 \%)$.

As respondentes que concluíram o curso nas décadas de 30 e 40, portanto em época anterior à Lei $775 / 49$, que disciplinou $o$ ensino da enfermagem no país, correspondem na área de ensino a 16 enfermeiras $(16,1 \%)$ e na área assistencial alcança nesta classe o maior percentual, $71,4 \%$ (55 enfermeiras).

$\mathrm{Na}$ década de 50, na vigência da Lei 775 , mas sem a exigência do curso colegial às candidatas das escolas de enfermagem, o percentual na área de ensino foi de 39 , ou seja, $39,4 \%$, na área assistencial o percentual nesta classe foi de $23,4 \%$, isto é, 18 enfermeiras.

Entre os anos de 61 a 70, em que já se exigia o curso secundário completo às estudantes de enfermagem que corresponde ao período de implantação da Lei de Diretrizes e Bases, formaramse da área de ensino 33 enfermeiras $(33,4 \%)$ e 3 enfermeiras de centros de saúde $(3,9 \%)$. Nos últimos 5 anos (19711975) se formaram $11 \%$ das respondentes que atuam em área de ensino e $1,3 \%$ das que atuam nos centros de saúde. Estas já são produto da Reforma Universitária de 1966/67.

No cômputo geral, podemos concluir que a maior parte das respondentes que trabalhavam em Escolas concluíram o curso no período da vigência da Lei $775 / 49$ e da Lei de Diretrizes e Bases $(72=72,8 \%)$. As exigências desta última caracterizavam o curso de enfermagem como de nível superior, mas ao reduzir a duração do curso, não incluiu a enfermagem de saúde pública como disciplina obrigatória e diminuiu o número de horas destinadas à prática. Do grupo de profissionais que trabalhavam em centros de saúde a maior parte $(50=71,4 \%)$ se formou antes da Lei $775 / 49$, devendo já se encontrar em final de carreira.

Assim temos que a população estudada caracteriza-se por se ter graduado 
CASTRO, I.B. e Colaboradores - O ensino e a prática da enfermagem em relação ao programa de controle da tuberculose no Estado do Rio de Janeiro. Rev. Bras. Enf.; DF, 33 : 318-355, 1980.

em sua grande maioria no Estado do Rio, tendo o grupo de docentes se graduado bem mais recentemente, donde se pode supor ser o mesmo mais jovem que $o$ de enfermeiras de centros de saúde.

- Preparo e experiência das enfermeiras docentes e de centros de saúde, relacionados ao controle da tuberculose

Parcelas consideráveis, 55,6\% (55 em 99) das professoras e $37,7 \%$ (29 em 77) das enfermeiras de centros de saúde não citaram cursos e/ou treinamentos nos quais tenham recebido informações de interesse para o controle da tuberculose. Entretanto $44(44,4 \%)$ professoras e $48(62,3 \%)$ enfermeiras de centros de saúde mencionaram tais cursos, sendo que as 44 professoras citaram 58 dessas atividades o que dà a média de 1,3 por profissional e as 48 enfermeiras de centros de saúde mencionaram 71 delas, o que dá a média de 1,5 por profissional.

A tabela 1 refere-se aos cursos e/ou treinamentos referidos por essas 92 respondentes.

Do total de cursos e/ou treinamentos citados, aqueles específicos sobre tuberculose apresentaram o mais alto percentual para o grupo assistencial (48 em $71=67,6 \%)$ ficando o grupo de ensino com 39,7\% (23 em 58).

A área docente apresentou o mais alto percentual no conjunto de cursos e/ou treinamentos em saúde pública, $43,1 \%$. A área de serviço ficou com $28,2 \%$ para esses cursos. Cursos e/ou treinamentos em áreas afins à saúde pública apresentaram $17,2 \%$ e $4,2 \%$ respectivamente, para as docentes e enfermeiras de centros de saúde.

A tabela II especifica o número de cursos e/ou treinamentos, nos quais as enfermeiras receberam informações sobre tuberculose. Verifica-se um total de
58 citações no grupo docente e 71 no grupo assistencial.

Vemos que, a partir de 1961, o envolvimento em cursos tanto na área docente quanto na área assistencial foi progressivamente mais acentuado, atingindo de 1961 a 1976 um total de 53 citações $(91,4 \%)$ no grupo docente e 67 $(94,4 \%)$ no grupo assistencial.

No período de 1971 a 1976, houve maior participação das respondentes das duas áreas: 22 em $58=37,9 \%$ na área docente e 41 em $71=57,8 \%$ da área assistencial, não atingindo entretanto a média de um curso ou treinamento por profissional, nesses seis anos $(0,5$ e 0,8 respectivamente).

Vale lembrar que, a partir de 1961, ocorreram alguns fatos que possivelmente mobilizaram os profissionais da área da saúde a se atualizarem.

Na segunda parte da década de 60 , a ênfase dos treinamentos foi relativa a provas tuberculínicas e vacinação BCG, pois era necessário efetuar o levantamento da prevalência na infecção tuberculosa no país e implantar a vacinação por via intradérmica.

No início das décadas de 60 e de 70 foram recomendados novos critérios de tratamento e alterados os esquemas terapêuticos.

A tabela III mostra que das 99 professoras das Escolas de Enfermagem $\mathbf{7 7}$ $(77,8 \%)$, depois de 1970 , além de sua atuação na área docente, desenvolvem também atividades na área assistencial, sendo que $47(47,5 \%)$ em Hospital Geral. As 21 que atuaram em centros de saúde $(21,2 \%)$ e as $5(5,1 \%)$ que atuaram em ambulatório isolado perfazem um total de $26(26,3 \%)$ que atuaram em serviços extra-hospitalares.

Das 77 enfermeiras dos centros de saúde, $25(26,0 \%)$, além dessa atividade, atuam em outros serviços, sendo que o maior percentual corresponde a Hospital Geral, $17(22,1 \%)$. Do total destas enfermeiras apenas $5(6,5 \%)$ trabalha- 
CASTRO, I.B. e Colaboradores - O ensino e a prática da enfermagem em relação ao prcgrama de controle da tuberculose no Estado do Rio de Janeiro. Rev. Bras. Enf.; DF, 33 : 318-355, 1980.

vam em Escolas de Enfermagem em periodo posterior a 1970 .

A tabela mostra que as experiências recentes dos professores em serviços extra-hospitalares são muito limitadas e as das enfermeiras de centros de saúde em ensino em escola de enfermagem, mais ainda; os maiores percentuais apresentados pelos dois grupos referemse a hospitais gerais; sendo bem maior para o grupo de professores. Este fato reflete a situação geral do mercado de trabalho.

Outra questão, relativa a instruções disponiveis sobre o programa de controse da tubercuiose, 1orneceu a inrormação de que das 10 uniaades mencionadas como campos de estagio, somente duas não dispõem de rotinas escritas. Assim, das $7 r i$ respondenies que trabalham nessas insticuições somente 4 enfermeiras $(5,2 \%)$ não contam com esse recurso.

A tabeia IV mostra a participação dos respondentes no Programa de Controle da Tuberculose, na cidade em que trabalhavam, em 1975 e/ou 1976.

A tabela indica que apenas 14 $(14,1 \%)$ das respondentes da área docente e $23(29,9 \%)$ da area assisiencial participaram do programa de controle da tuberculose de suas cidades. Verifica-se que, apesar de a área assistencial ter tido maior participaçáo nos programas de controle ảa tuberculose, o que se justifica por estarem no próprio campo em que se ciesenvolvem os programas, esta participação ainda é restrita, considerando-se a tendência de integrar as atividades desse programa às atividades gerais do centro de saúde.

A tabela $\mathrm{V}$ apresenta a proporção de profeszores e cie enfermeiras de centros de saude que participaram do en-. sino cie enfermagem em 1975 e 1976, no que se refere à tuberculose.

Cbserva-se que $30,3 \%$ das professoras e apenas $10,4 \%$ das enfermeiras de centros de saúde participaram desse ensino.

Pode-se notar que os percentuais de professoras docentes que não participam do programa de controle da tuberculose é praticamente tão elevado $(82,9 \%)$ quanto o de enfermeiras de centros de saúde que não participam do ensino, no que interessa a esse controle $(81,8 \%)$.

A tabela VI mostra o tipo de participação e o número de horas gastas pelas respondentes distribuídas entre professoras e enfermeiras de centros de saúde no programa de centrole da tuberculose.

Dentre o total de respondentes, 14 professoras informaram haver participado de algum modo de programa de controle da tuberculose $(14,1 \%)$ e 23 das enfermeiras de centros de saúde $(29,9 \%)$. A média de horas gastas, por profissional, foi de 36,6 horas para 0 primeiro grupo e de 43,1 horas para o segundo.

Verifica-se que a participação tanto em termos de número de enfermeiras como em número total de horas em ambos os grupos é mais significativa na área de "Execução direta das atividades" da qual participaram 9 enfermeiras docentes $(64,3 \%)$ e 14 de centros de saúde $(60,9 \%)$ com uma média de horas gastas por enfermeira de 32,7 horas para o primeiro grupo e de 56,7 horas para o segundo. Nestas atividades foram gastas 295 horas $(57,6 \%$ do número total de horas) gastas pelas professoras no programa de controle da tuberculose e 795 horas $(80,1 \%)$ pelo grupo assistencial.

Em segundo lugar figura o "Planejamento e/ou avaliação do programa de controle da tuberculose", atividade da qual paríciparam 8 enfermeiras docentes $(57,1 \%)$ e 11 de centros de saúde $(47,8 \%)$, com médias de horas por profissional de 22,5 horas e 9,2 horas, respectivamente. Nestas atividades, foram 
CASTRO, I.B. e Colaboradores - O ensino e a prática da enfermagem em relação ao programa de controle da tuberculose no Estado do Rio de Janeiro. Rev. Bras. Enf.: DF, 33 : 318-355, 1980.

gastas 181 horas $(35,4 \%)$ pelo grupo docente e 102 horas $(10,3 \%)$ pelo grupo assistencial.

A “organização e/ou reorganização do serviço, no que se refere à tuberculose" obteve o terceiro lugar no grupo de enfermeiras docentes. No grupo de enfermeiras de centros de saúde este lugar é ocupado pelo "treinamento de pessoal de serviço para atividades de controle da tuberculose". Note-se entretanto que aquela atividade administrativa obteve nesse grupo de centros de saúde média ligeiramente superior, não só a treinamento de pessoal, bem como a planejamento e/ou avaliação de programa.

A tabela VII dá uma visão panorâmica do grupo de enfermeiras que exerceram atividades de ensino para o controle da tuberculose. Dentre o total de respondentes, 30 docentes $(30,3 \%)$ e 8 enfermeiras de centros de saúde $(10,4 \%)$ declararam haver participado do ensino sobre o controle da tuberculose. A média de horas gastas por profissional foi de 48,9 para o primeiro grupo e de 147,2 para o segundo.

No grupo das professoras o maior percentual com relação a horas gastas foi encontrado na atividade de "supervisão de estágio", com 968 horas $(66,0 \%)$, com uma média de 44 horas/professor.

Já o grupo assistencial, 5 enfermeiras contribuiram com 335 horas $(28,4 \%)$ para a supervisão de estágio com uma média de 67,0 horas/enfermeira. Valor semelhante tem a "participação da avaliação do ensino sobre tuberculose" 330 horas $(28,0 \%)$ à qual se dedicaram igual número de enfermeiras e com média horária semelhante, e número de horas muito superior às do grupo docente (109 horas trabalhadas por 13 professoras); do mesmo modo na programação do ensino o grupo assistencial teve maior participação em número de horas: 240 horas trabalhadas por 1 enfermeira contra 69 horas trabalhadas por 11 professoras.

"Demonstração e/ou exercícios" também contribuiu com 5 enfermeiras, embora com uma média bem menor $(32,8)$ horas/enfermeira. No grupo de docentes as atividades de demonstração e/ou exercícios com 182 horas $(12,4 \%)$ e uma média de 14 horas por professor.

Podemos observar que as docentes apresentaram um maior número de horas gastas no ensino do que as enfermeiras de centros de saúde. Entretanto, estas obtiveram médias muito superiores às das professoras em todas as atividades estudadas, sendo a diferença global de 147,2 para 48,9. Chama a atenção, que tanto no programação como na avaliação do ensino as enfermeiras de centros de saúde trabalharam em número de horas superior aos das professoras.

E interessante notar que o número de horas gastas, por ambos os grupos, com o ensino é inferior ao número de horas gastas com o programa de controle da tuberculose, embora um maior numero de professoras tenha participado do número do que do serviço e as de centros de saúde ao inverso participaram em maior número do programa cle controle do que do ensino.

A tabela VIII dá uma visão panorâmica do grupo de 176 enfermeiras, distribuídas segundo as instituições a que pertencem e sua experiência prática ria técnica de BCG intradérmico e em consuitas de enfermagem com pacientes tuberculosos.

Das 99 enfermeiras respondentes e em exercício nas Escolas de Enfermagem encontramos $48(48,5 \%)$ que nunca aplicaram a vacina BCG por via intradérmica, contra $21(27,3 \%)$ das de centros de saúde.

Com até 50 experiências na técnica de BCG encontramos 11 enfermeiras 
CASTRO, I.B. e Colaboradores - O ensino e a prática da enfermagem em relação ao programa de controle da tuberculose no Estado do Rio de Janeiro. Rev. Bras. Enf.; DF, 33 : 318-355, 1980.

docentes $11,1 \%$ e $8(10,4 \%)$ de centros de saúde.

Com 60 aplicações e mais, número considerado pela DNPS como o mínimo necessário à aquisição de destreza, encontramos $15(5,1 \%)$ enfermeiras docentes e $24(31,2 \%)$ enfermeiras de centros de saúde.

Em relação à consulta de enfermagem encontramos 37 docentes $(37,4 \%)$ e 17 enfermeiras de centros de saúde sem experiência nesta atividade.

Com mais de 60 e até mais de uma centena de experiências encontramos no grupo docente os mesmos $14(14,1 \%)$ encontrados nas vacinações e $27(35,1 \%)$ no grupo assistencial.

Vemos assim que o grupo do centro de saúde apresenta maior experiência do que o de docentes quanto à vacinação intradérmica e à consulta a portadores de tuberculose. Essa experiência parece ser ligeiramente maior para a consulta do que para a vacinação.

As tabelas IX e X apresentam a opinião das enfermeiras quanto a sentiremse preparadas para desenvolver outras atividades relacionadas à tuberculose, além das já realizadas.

Podemos verificar que mais de $69,7 \%$ das profissionais atuantes nas escolas de enfermagem e $58,4 \%$ nos centros de saúde não estão preparadas para assumir novas atividades no campo da tuberculose. Apenas um pequeno percentual de enfermeiras $(16=16,2 \%)$ professoras e de enfermeiras da área de saúde $(15=19,5 \%)$ sentem-se aptas para o desenvolvimento de outras tarefas. Dessas, grande parte das enfermeiras de centros de saúde $(11=73,3 \%)$ e quase um terço dessas profissionais $(5=31,5 \%)$ declararam-se aptas a desenvolver toda e qualquer atividade de controle da tuberculose. Dentre as outras atividades que as respondentes acham que poderiam desenvolver no campo da tuberculose, observam-se pe- quenos percentuais para as atividades de prevenção, descoberta e controle da tuberculose. Estes percentuais apresentam apenas pequenas variações nos dois grupos de respondentes, porém sem significação estatística. Duas professoras mencionaram que poderiam desenvolver pesquisas.

O conjunto das dez tabelas anteriores parece evidenciar que as enfermeiras dos centros de saúde estudados, além de terem mais experiência nas atividades de controle da tuberculose, têm participado mais de atividades de atualização profissional a ela relacionadas, do que as professoras das escolas de enfermagem. As experiências profissionais dos dois grupos, além do emprego de professora e de enfermeira de centros de saúde, respectivamente, não são de molde a contribuir de modo específico para o aumento da capacidade profissional, relacionada ao programa de controle da tuberculose e/ou ao ensino dos aspectos a ele relacionados. Parece que as enfermeiras dos centros de saúde têm contribuído mais no ensino dos estudantes do que as professoras têm contribuído para o programa de controle da tuberculose. Entretanto, parece que esta contribuição se dá mais em nível de atividades práticas, possivelmente no próprio campo de estágio. Isto poderia talvez explicar porque $81,8 \%$ das enfermeiras de centros de saúde declararam não participar do ensino de enfermagem, no que se refere à tuberculose, por inteıppretarem como ensino apenas aquele ministrado na escola de enfermagem.

Não obstante, a auto-avaliação dessas enfermeiras, nos dois grupos, não é muito otimista, quanto a sentirem-se, no momento, capazes de expandir suas atividades relacionadas ao controle da tuberculose. Cerca de 5\% do grupo de professoras e de $14 \%$ do grupo de enfermeiras de centros de saúde declararam ter o domínio da área, o que parece 
CASTRO, I.B. e Colaboradores - O ensino e a prática da enfermagem em relação ao programa de controle da tuberculose no Estado do Rio de Janeiro. Rev. Bras. Enf.; DF, 33 : 318-355, 1980.

configurar a existência, em ambas as áreas, de especialistas.

- Concordância entre as opiniões e atitudes das professoras e enfermeiras de centros de saúde e as normas recomendadas pela DNPS e à tendência de integração das ativiaades de controle da tuberculose dos serviços gerais de saúde.

A tabela XI mostra as opiniões das respondentes sobre o tipo de orientação que deve ser dada aos clientes tuberculosos quanto aos seus hábitos de vida.

No que toca à alimentação $46,8 \%$ e $52,5 \%$ (52 em 99) do grupo docente e (36 em 77) das respondentes do grupo assistencial acham que os clientes devem ser orientados para uma superalimentação; 37,4\% (37 em 99) do grupo docente indicariam alimentação habitual, bem como $53,2 \%$ (41 em 77) do grupo assistencial.

Quanto à atividade física $55,6 \%$ do grupo docente (55 em 99) e 64,4\% (50 em 77) do grupo assistencial indicaram repouso; $33,3 \%$ (33 em 99 ) e $33,8 \%$ (26 em 77) diriam ao paciente que continuasse com suas atividades habituais.

A orientação a respeito dos cuidados de higiene é preocupação de 73,7\% (73 em 99) da área docente e 76,6\% (59 em 77) da área assistencial. Estas enfermeiras recomendariam a separação dos utensílios enquanto que apenas $17,2 \%$ (17 em 99) das docentes e $23,4 \%$ enfermeiras dos serviços (18 em 77) diriam que os utensílios poderiam ser comuns.

Sobre a dormida $83,8 \%$ (83 em 99) das enfermeiras do grupo docente e $71,4 \%$ (55 em 77) das enfermeiras do grupo assistencial orientariam para que dormissem separados.

Estes dados mostram que as respondentes não descartaram conceitos antigos e superados com relação à importância da alimentação e do repouso no tratamento da tuberculose. Permanecem também com o conceito de transmissão indireta, por via digestiva, evidenciado na recomendação de separação dos utensílios. O conceito da quimioterapia como medida profilática não foi totalmente assimilado, uma vez que 83 $(83,8 \%)$ e $55(71,4 \%)$ enfermeiras dos dois grupos indicaram a dormida separada. Vale lembrar que o maior risco de contágio dos comunicantes ocorre antes do início do tratamento do doente.

A análise desta tabela leva a crer que as normas recomendadas pela DNPS no que diz respeito à orientação dos clientes não são aceitas por grande maioria de cada um dos dois grupos estudados.

A tabela XII refere-se à opinião das respondentes sobre os setores mais indicados para o desenvolvimento das atividades de controle da tuberculose.

$53(53,6 \%)$ respondentes do grupo de ensino e $27(35,1 \%)$ do grupo assistencial acham que todos os setores das Unidades Sanitárias deveriam desenvolver atividades de tuberculose.

$14(14,1 \%)$ da área de ensino e 29 $(37,6 \%)$ da área assistencial julgam que essas atividades deveriam ser desenvolvidas pelos dispensários de tuberculose.

$23(23,2 \%)$ da área de ensino e 16 $(20,8 \%)$ da área assistencial acham que tanto os setores da Unidade de Saúde como o dispensário de tuberculose deveriam desenvolver as atividades de controle da tuberculose.

Nesta tabela merece destacar a opinião de $37,6 \%$ das enfermeiras de centros de saúde que permanecem com a opinião de que essa atividade ainda deveria ser desenvolvida por serviços especializados.

A tabela XIII mostra a opinião das respondentes quanto à hospitalização de pacientes em hospital geral, quando acometidos de outro problema de saúde.

Os maiores percentuais mostram que as respondentes do grupo docente 72 $(72,7 \%)$ são de opinião que os doentes portadores de tuberculose, acometidos 
CASTRO, I.B. e Colaboradores - O ensino e a prática da enfermagem em relaçảo a o programa de controle da tuberculose no Estado do Rio de Janeiro. Rev. Bras. Enf́.; DF, 33 : 318-355, 1980.

de outro problema de saúde, devem ser internados em hospital geral, enquanto que $42(54,5 \%)$ enfermeiras da área assistencial têm opinião contrária.

Os dados das tabelas XII e XIII mostram que as opiniões das enfermeiras da área de ensino estão mais de acordo com a atual política da DNPśs de integrar as atividades da tuberculose nas atividades dos serviços gerais de saúde. Vale lembrar que a DNPS já adotou nas suas unidades de administração direta a medida de diversificar sua clientela, internando clientes não tuberculosos (outras doenças transmissíveis, outras pneumopatias).

A tabela XIV aponta as razões das 42 enfermeiras do grupo de ensino e de 31 do grupo assistencial que são favoráveis à hospitalização de tuberculosos em hospitais gerais.

No grupo das 72 professoras que responderam afirmativamente observase que $63(87,5 \%)$ acham que o tratamento da tuberculose exige medidas de isolamento simples, vindo a seguir 16 respostas $(22,5 \%)$ para a não exigência de profissionais especializados; a menos apontada foi a razão de facilitar a internação.

As $31(42,0 \%)$ enfermeiras do grupo assistencial opinam de modo semelhante ao das enfermeiras docentes.

A tabela XV aponta as razões das 20 enfermeiras de escolas e de 42 de centros de saúde para a não hospitalização do tuberculoso em hospital gerai.

Uma proporção aproximada de docentes e de enfermeiras de centros de saúde $(75,0 \%$ e $73,8 \%$ respectivamente $)$ julgam que tal medida seria perigosa para os demais pacientes do hospital.

Algumas acharam que seria perigoso para a equipe do hospital. Esta resposta obteve percentual muito mais alto para as enfermeiras dos centros de saúde do cue para as de escolas de enfermagem $(57,1 \%$ e $15,0 \%$ respectivamente $)$.
Vale ressaltar que 34 enfermeiras de centros de saúde $(81,0 \%$ - o maior percentual para esse grupo) e 10 de escolas $(50,0 \%)$ temem que o tratamento da tuberculose não seja seguido durante a hospitalização.

- Expectativas cias enfermeiras docentes e de centros de saúde quanto às capacidades consideradas imprescindíveis a uma enfermeira recémformada, para atuar em um programa de controle da tuberculose.

A tabela XVI mostra a opinião das enfermeiras sobre um elenco de atividades sugerido pelas autoras, como essenciais a uma recém-graduada, para atuar num programa de controle de tuberculose.

O baixo percentual observado na citação de atividades básicas desenvolvidas pelo serviço de enfermagem num programa de controle da tuberculose, parece demonstrar que as enfermeiras docentes não estão seguras sobre qual deve ser a contribuição da enfermeira em programas desta natureza. Entretanto ambos os grupos valorizaram mais as atividades ligadas diretamente ao atendimento da clientela.

De modo geral as atividades foram mais valorizadas pelo grupo de serviço do que pelo grupo de ensino. As atividades relacionadas à vacinação, às provas tuberculínicas, à consulta de enfermagem, à visita domiciliar, ao controle do tratamento e a palestras educativas foram indicadas por $81,8 \%$ a $96,1 \%$ (63 a 74) das enfermeiras de serviço; o grupo de professoras manifestou-se em percentuais bem menores: $40,4 \%$ a $46,5 \%$ (40 a 46).

As atividades de administração e supervisão foram valorizadas por metade das enfermeiras de centros de saúde $39=50,6 \%$ ) e por nenhuma das de escolas. As atividades ligadas à progra- 
CASTRO, I.B. e Colaboradores - O exsino e a prática da enfermagem em relação ao programa de controle da tuberculose no Estado do Rio de Janeiro. Rev. Bras. Enf.: DF, 33 : 318-355, 1980.

mação foram consideradas essenciais por $39,0 \%$ (30) das enfermeiras de centros de saúde e por $24,2 \%$ (24) das docentes.

A tabela XVII informa a opinião das respondentes sobre as dificuldades que teria que superar uma enfermeira não especializada, para prestar assistência a pacientes tuberculosos e suas famílias.

A maior dificuldade apontada por ambos os grupos foi o desconhecimento das normas de controle da tuberculose, apontada por $81,8 \%$ das enfermeiras de centros de saúde (63) e por $56,6 \%$ das professoras (56). A seguir aparece a falta de destreza para a técnica de vacinação intradérmica e para a aplicação das provas tuberculínicas e as dúvida's quanto ao modo de desenvolver a consulta ou entrevista de enfermagem e a orientação da família do paciente. Esses itens obtiveram de $64,9 \%$ a $77,9 \%$ no grupo de enfermeiras de centros de saúde (50 a 60) e de 41,4 a $45,5 \%$ (41 a 45 ) no grupo de docentes. Como evitar o contágio foi dificuldade apontada por $51,9 \%$ das enfermeiras de centros de saúde (40) e por $26,3 \%$ (26) das docentes.

Analisando esta tabela chegamos à conclusão de que a visão das enfermeiras de serviço a respeito do preparo das enfermeiras recém-graduadas é maiss pessimista do que a de suas colegas professoras, pois praticamente todas as dificuldades foram reconhecidas como tal por um maior percentual do grupo de serviço.

Os achados das tabelas XVI e XVII sugerem a necessidade de aproximação entre serviços e escolas de modo a aperfeiçoar o preparo dos estudantes nesses aspectos.

- Preparo dos estudantes de enfermagem quanto aos aspectos relacionados ao controle da tuberculose.
$\mathrm{Na}$ tabela XVIII as respondentes da área de ensino e da área assistencial indicam as atividades desenvolvidas pelos alunos de enfermagem durante o período de estágio.

As atividades mais citadas peios dois grupos, embora não exatamente na mesma ordem, foram a realização de provas tuberculínicas $(83,1$ e $62,6 \%)$, a visita domiciliária $(72,7$ e $55,6 \%)$, a vacinação $(66,2$ e $59,6 \%)$, a coleta de escarro $(64,9$ e $50,5 \%)$, a consulta de enfermagem (ou entrevista) 61,0 e 44,4\%, a administração $(83,1$ e $43,4 \%)$ ou distribuição de medicamentos $(55,8$ e $45,5 \%$ ) e a procura de casos na clientela geral $(40,3$ e $38,4 \%)$.

Vale notar que a administração de medicamentos, tarefa que não é específica ao controle da tuberculose, recebeu no grupo de serviço o mais alto percentual encontrado. Outras atividades características do pessoal auxiliar também foram citados com mais freqüência do que a consulta de enfermagem, que seria a atividade característica, e que obteve o primeiro lugar na opinião das professoras, sobre o que seria imprescindivel a uma enfermeira para atuar em um programa de controle da tuberculose. A procura de casos na clientela geral, atividade que deveria ser desenvolvida pelas enfermeiras em todas as áreas de atuação obteve percentuais muito baixos $(40,3$ e $38,4 \%)$. De um modo geral, verifica-se não haver grandes discordâncias nas citações das feitas pelas enfermeiras dos dois grupos. No grupo de serviço na tabela XVI a consulta obteve $85,7 \%$ das opiniões e na tabela XVII $71,4 \%$ desse grupo considerou que o desenvolvimento dessa atividade se constituiria em dificuldade para a participação de uma enfermeira no programa de controle da tuberculose. Entretanto, mais uma vez os percentuais foram mais altos para o grupo de serviço, em praticamente todos os itens. Constituiu exceção o aprazamento e o 
CASTRO, I.B. e Colaboradores - O ensino e a prática da enfermagem em relação ao programa de controle da tuberculose no Estado do Rio de Janeiro. Rev. Bras. Ene.; DF, 33 : 318-355, 1980.

controle do comparecimento dos doentes, que foi o único item que obteve maior percentual das enfermeiras docentes do que dos centros de saúde, $61,6 \% \quad(61)$ e $57,1 \%$ (44), respectivámente.

A tabela XX mostra a opinião dos dois grupos de enfermeiras estudados, com relação à necessidade de modificar o preparo dos estudantes de enfermagem, no que se refere à tuberculose.

Comparando as respostas das profissionais por área de atuação, verificamos que o maior percentual de respostas afirmativas foi encontrado no grupo de enfermeiras docentes $(73,7 \%=73$ enfermeiras $)$. Neste grupo de professoras apenas $10(10,1 \%)$ acham o ensino satisfatório. Já no grupo assistencial 45 enfermeiras $(58,4 \%)$ concordaram com a necessidade de mudança e $17(22,1 \%)$ deram respostas negativas.

Verifica-se assim que a necessidade de mudança no preparo de estudantes é mais sentida entre os profissionais docentes do que entre aqueles que trabalham nos centros de saúde.

A tabela $\mathrm{XX}$ mostra a opinião dos grupos estudados, referentes aos aspectos mencionados pelas autoras como possíveis modificações na área de ensino da tuberculose.

Os maiores percentuais apresentados nos dois grupos se referem a "incentivar o entusiasmo em relação ao programa de controle da tuberculose", o que parece demonstrar uma aspiração por um ensino mais realista e produtivo. A seguir vêm as necessidades de desenvolver maiores habilidades relacionadas às consultas e visitas $(55,6 \%$ e $49,4 \%$, respectivamente para o grupo docente e o assistencial), e para a vacinação e as provas tuberculínicas $(47,4$ e $46,8 \%$, respectivamente).

O ensino de aspectos teóricos relacionados à tuberculose, incluídos nas disciplinas básicas como Bacteriologia,
Imunologia, Epidemiologia e sobre o diagnóstico e o tratamento da tuberculose foi mais valorizado pelo grupo de professoras $(55=55,6 \%$ para os dois itens) do que pelas enfermeiras de centros de saúde $(27=35,1 \%$ e $23=29,9 \%$, respectivamente). Quanto ao grupo de enfermeiras de centros de saúde, observamos que as modificações recomendadas, foram para os temas mais diretamente ligados à prática.

A tabela XXI refere-se à opinião das respondentes, sobre quem deve dar consultas de enfermagem ao cliente tuberculoso.

$53,6 \%$ (53 em 99) do grupo de ensino e $53,2 \%$ das respondentes (41 em 77 ) da área assistencial acham que a consulta de enfermagem deve ser feita exclusivamente pela enfermeira.

As demais respondentes acham que, além da enfermeira, outros elementos da equipe também devem executar esta atividade. $25(25,2 \%$ do grupo docente e $18(23,4 \%)$ do grupo assistencial acham que, além da enfermeira, o técnico de enfermagem e/ou o auxiliar de enfermagem e/ou a visitadora sanitária podem executá-la.

$2,0 \%$ (2 em 99) das docentes e $6,5 \%$ (5 em 77) da área assistencial acham que todos da equipe de enfermagem, inclusive o atendente, podem desenvolver essa atividade.

\section{DISCUSSÃO E CONCLUSÓES}

Os resultados apresentados no capítulo anterior complementam as informações daquele trabalho mencionado no primeiro capítulo. Aquele feito a nível de instituições (escolas de enfermagem e secretarias de saúde) e este a nível de profissionais (enfermeiras professoras de escolas de enfermagem e enfermeiras de centros de saúde).

A conclusão central de então foi a de que "no Brasil existe um círculo vi- 
CASTRO, I.B. e Colaboradores - O ensino e a prática da enfermagem em relação ao programa de controle da tuberculose no Estado do Rio de Janeiro. Rev. Bras. Enf.; DF, 33 : 318-355, 1980.

cioso - os cursos de enfermagem não estão orientados de modo a preparar profissionais capazes de atuar imediatamente em programas de controle de tuberculose integrados nos serviços gerais de saúde; ao mesmo tempo, esses serviços não estão proporcionando aos estudantes modelos adequados de desempenho".

Esta afirmação foi comprovada, no atual estudo, pelas opiniões e informações emitidas pelos dois grupos estudados. Além dessa, podemos tirar outras conclusões mais específicas:

- Os dois grupos de enfermeiras estucados apresentam características diversas correspondendo inclusive a momentos diferentes do ensino da enfermagem no Brasil. O fato de que o grupo de centros de saúde ser bem mais antigo na profissão poderia significar que as secretarias de Saúde nảo estão renovando scus quadros ou que as enfermeiras procuram trabailıar nesses serviços no final de suas carreiras. Nenhuma das duas alternativas é muito animadora.

- Apenas urna pequena proporção de enfermeiras de cada grupo (maior entretanto no grupo de serviço) julga-ie proticiente no que se refere às atividades de controle da tuberculose. um todo caso, o grupo de serviço parece ter mais experiência e estar mais atualizado a este respeito do que o grupo docente. A interaçāo entre os dois grupos parece dar-se apenas a nível de campo de estágio, com uma contribuição maior por parte das enfermeiras de centros de saúde no ensino, do que das professoras no desenvolvimento do programa. De acordo com os princípios e proposições da integração docente-assistencial, reconhecida como fator decisivo para a adequação do ensino à realidade, esta interação dever-se-ia processar tanto em nível de serviço co- mo no de escola e nos dois sentidos. No atual trabalho não foi estudada a contribuição que o estudante, como terceiro elemento envolvido nesse processo de integração, dá no campo de estágio. Entretanto, os tipos de atividades que as enfermeiras informam serem por eles executados, além de não serem adequados à. sua formação profissional, não parecem configurar um bom aproveitamento dessa categoria como recursos humanos.

- No que se refere às normas preconizadas pela DNPS, as mesmas ou são desconhecidas ou não são aceitas pela maioria dos dois grupos; entretanto o grupo docente aceita melhor a atual política da DNPS de integrar as atividades de controle da tuberculose às atividades gerais de saúde. A recente edição de dois manuais, um de normas e outro de procedimentos, com tiragem de dez mil exemplares, virá favoracer a divulgação dessas normas.

- As enfermeiras de centros de saúde delinearam com mais clareza sua opinião sobre quais devem ser as atividades da enfermeira no programa de controle da tuberculose, do cue suas colegas professoras. As atividades relacionadas à proteção direta de serviço à clientela foram as mais valorizadas por ambos os grupos, como imprescindiveis a uma enfermeira recém-formada para atuar em um tal programa.

- Não parece haver uma adequação do preparo do estudante de enfermagem ao programa de controle da tuberculose. A insatisfação quanto ao ensino, pelo menos no que se refere aos aspectos de tuberculose, é maior no próprio grupo de professoras. A principal sugestão de ambos os grupos, para a melhoria desse ensino, é justamente dar mais ênfase ao progra- 
CASTRO, I.B. e Colaboradores - O ensino e a prática da enfermagem em relação ao programa de controle da tuberculose no Estado do Rio de Janeiro. Rev. Bras. Enf.; DF, 33 : 318-355, 1980.

ma de controle. Na verdade, a insatisfação com o ensino é generalizada em nossos dias. Em relação à graduação em Enfermagem há várias tentativas de reformulação curricular em andamento, a maioria das quais enfatizando os aspectos da formação e procurando adequar a prática estudantil à realidade dos nossos serviços e às necessidades de saúde de nossas populações (Ver Anais do XXX Congresso Brasileiro de Enfermagem - 1978). Além disso, a Comissão de Especialistas de Ensino de Enfermagem, criada pela Secretaria de Ensino Superior do MEC, estuda no momento a oportunidade de uma reforma do Currículo Mínimo do Curso de Graduação em Enfermagem.

- Não há consenso em qualquer dos grupos estudados sobre quem pode e deve dar consultas a pacientes de tuberculose. Este achado é de certa forma surpreendente, pois não confirma aqueles de estudo exploratório sobre a consulta de enfermagem CAsTRO (1975). Além disso, o anteprojeto de lei referente ao exercício profissional da enfermagem, elaborado pelo COFEN, com ampla participação das entidades de classe em todo o Brasil, prevê a consulta de enfermagem como uma das duas únicas atividades de assistência direta reservada à enfermeira. Para aclarar a questão, a ABEn, atendendo a recomendação a ela dirigida pelo XXX Congresso Brasileiro de Enfermagem, estará promovendo durante este XXXI Congresso, um Comitê de Especialistas que deverá elaborar parecer sobre o assunto.

\section{RECOMENDAÇÓES}

\section{1 - Considerando}

a) não haver uma adequação do preparo do estudante de enfermagem aos programas de saúde desenvolvidos pelo aparelho utilizador de recursos humanos.

b) que a principal medida corretiva para esta situação seria a de dar mais ênfase, no ensino, aos programas de saúde em andamento.

1 - Recomenda-se

Às Secretarias de Saúde e aos diversos órgãos do Ministério da Saúde:

- que prestem assessoria técnica aos cursos de enfermagem, de modo a que seja adequado às necessidades desses serviços.

Aos Cursos de Enfermagem:

- que incluam entre seus objetivos finais aqueles indispensáveis à participação da enfermagem nos programas de saúde.

\section{2 - Considerando}

a) que a inexistência de uma metodologia da consulta de enfermagem contribui para que esta seja às vezes considerada como atividade delegível.

b) que 0 anteprojeto de lei do exercício profissional de enfermagem, proposto pelo COFEN, a partir de subsídios enviados de todas as partes do país, prevê a consulta de enfermagem como prerrogativa da enfermeira. 
CASTRO, I.B. e Colaboradores - O ensino e a prática da enfermagem em relação ao programa de controle da tuberculose no Estado do Rio de Janeiro. Rev. Bras. Enf.; DF, 33 : 318-355, 1980.

2 - Recomenda-se

Aos serviços de saúde que atendem a pacientes não hospitalizados:
- que promovam estudos no sentido de desenvolver metodologias apropriadas à situação de consultas de enfermagem adequadas às suas clientelas específicas.

TABELA I

Cursos e/ou treinamentos de interesse para o programa de controle da tuberculose de que participaram professores de enfermagem e enfermeiras de centros de saúde depois de concluírem o curso de enfermagem.

\begin{tabular}{|c|c|c|c|c|}
\hline \multirow{2}{*}{$\begin{array}{l}\text { ASSUNTO DO } \\
\text { TREINAMENTO }\end{array}$} & \multicolumn{2}{|c|}{ ESC. ENF. } & \multicolumn{2}{|c|}{ C. SAŨDE } \\
\hline & $N^{9}$ & : & $N^{\circ}$ & $\because$ \\
\hline T U B B E & 23 & 39.7 & 48 & 67,6 \\
\hline 1 - Treinamento e/ou atualização & 13 & 22,4 & 16 & 22,6 \\
\hline 2 - Treinamento PPD e/ou BCG Intradérmico & 4 & 6,9 & 12 & 16,9 \\
\hline 3 - Jornada ou Seminärio & 3 & 5,2 & 15 & 21,1 \\
\hline 4 - Estágio & 3 & 5,2 & - & - \\
\hline 5 - Palestras & - & - & 5 & 7,0 \\
\hline 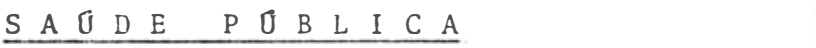 & 25 & 43,1 & 20 & 28,2 \\
\hline 1 - Mestrado em Saúde Pública & 4 & 6,9 & 1 & 1.4 \\
\hline 2 - Especializaçāo em Saúde Pública & 16 & 27,7 & 17 & 24,0 \\
\hline 3 - Planejamento do Setor Saúde. & 1 & 1,7 & - & \\
\hline 4 - Curso de atualizaçāo e/ou Seminārio & 2 & 3,4 & 1 & 1,4 \\
\hline 5 - Educação Sanitária & - & - & 1 & 1,4 \\
\hline 6 - Higiene do Trabalho & 2 & 3,4 & - & - \\
\hline A F I N S & 10 & 17,4 & 3 & 4,2 \\
\hline 1 - Licenciatura em Enfermagem & 2 & 3,4 & - & - \\
\hline $\begin{array}{l}2 \text { - Aperfeiçoamento em Didática e Pedagogia } \\
\text { aplicada em Enfermagem }\end{array}$ & 3 & 5,2 & 1 & 1,4 \\
\hline 3 - Administração em Saúde & 1 & 1,7 & - & - \\
\hline 4 - Supervisāo & 1 & 1,7 & - & - \\
\hline 5 - Administração Hospitalar & - & - & 1 & 1,4 \\
\hline 6 - Curso de Epidemiologia e Obstetrícia & 1 & 1,7 & 1 & 1,4 \\
\hline $\begin{array}{l}7 \text { - Imunologia, Parasitologia, Doenças Trans } \\
\text { missiveis }\end{array}$ & 2 & 3,4 & - & - \\
\hline $\mathrm{T} O \mathrm{TA} \mathrm{L}$ & 58 & 100,0 & 71 & 100,0 \\
\hline
\end{tabular}

Obs.: ESC. ENF. = Escola de Enfermagem - C. SAƯDE = Centro de Saúde. Média de cursos e/ou treinamentos por respondentes: 1,3 para professores e 1,5 para enfermeiros de centro de saúde. 
CASTRO, I.B. e Colaboradores - O ensino e a prática da enfermagem em relação ao programa de controle da tuberculose no Estado do Rio de Janeiro. Rev. Bras. Enf.; DF, 33 : 318-355, 1980.

TABELA II

Ano de realização de curso e/ou treinamento feito por professoras e enfermeiras de centros de saúde

\begin{tabular}{|c|c|c|c|c|c|}
\hline \multirow{2}{*}{\multicolumn{2}{|c|}{$\begin{array}{l}\text { LOCAL DE TRA- } \\
\text { ANO DO CURSO BALHO } \\
\text { E/OU TREINAMENTO } \\
\end{array}$}} & \multicolumn{2}{|c|}{ ESC.ENFERMAGEM } & \multicolumn{2}{|c|}{ CENTRO DE SAODE } \\
\hline & & $N^{9}$ & : & $\mathrm{N}^{8}$ & $\xi$ \\
\hline 1951 & 1955 & 1 & 1,7 & 1 & 1,4 \\
\hline 1956 & 1960 & 4 & 6,9 & 3 & 4,2 \\
\hline : 1961 & 1965 & 15 & 25,9 & 9 & 12,7 \\
\hline 1966 & 1970 & 16 & 27,6 & 17 & 23,9 \\
\hline 1971 & 1976 & 22 & 37,9 & 41 & 57,8 \\
\hline $\mathrm{T} O \mathrm{~T} \mathrm{AL}$ & & 58 & 100,0 & 71 & 300,0 \\
\hline
\end{tabular}

Obs.: Média de cursos e/ou treinamentos por respondentes no período 1971-1976: 0,5 para professoras e 0,8 para enfermeiras de centros de saúde. 
CASTRO, I.B. e Colaboradores - O ensino e a prática da enfermagem em relação ao programa de controle da tuberculose no Estado do Rio de Janeiro. Rev. Bras. Enf.; DF, 33 : 318-355, 1980.

TABELA III

Instituições em que trabalharam ou trabalham as enfermeiras respondentes, de 1970 em diante

\begin{tabular}{|c|c|c|c|c|}
\hline \multirow{2}{*}{ DE INSTITUIÇ.OES } & \multicolumn{2}{|c|}{ ESC. ENFERMAGEM } & \multirow{2}{*}{$\frac{\text { CENTR }}{N^{\circ}}$} & \multirow{2}{*}{$\frac{\text { SAODE }}{?}$} \\
\hline & Ne & 8 & & \\
\hline ESCOLA DE ENFERMACEM & 99 & 100,0 & 5 & 6,5 \\
\hline CENTRO DE SAODE & 21 & 21,2 & 77 & 100,0 \\
\hline HOSPITAL GERAL & 47 & 47,5 & 17 & 22,1 \\
\hline HOSPITAL DE TUBERCULOSE & 2 & 2,0 & - & - \\
\hline OUTRO HOSPITAL ESPECIALIZADO & 2 & 2,0 & 2 & 2,6 \\
\hline AMBULATORIO ISOLADO & 5 & 5,1 & 1 & 1,3 \\
\hline NIVEL CENTRAL & - & - & 1 & 1,3 \\
\hline
\end{tabular}


CASTRO, I.B. e Colaboradores - O ensino e a prática da enfermagem em relação ao programa de controle da tuberculose no Estado do Rio de Janeiro. Rev. Bras. Enf.; DF, 33 : 318-355, 1980.

TABELA IV

Participação das enfermeiras respondentes no programa de controle da tuberculose da cidade em que trabalhavam em 1975 e/ou 1976

\begin{tabular}{|c|c|c|c|c|}
\hline \multirow{2}{*}{$\begin{array}{l}\text { WQCAL DE TRA- } \\
\text { PART ICIPAÇAOO }\end{array}$} & \multicolumn{2}{|c|}{ ESCOLA DE ENFERMAGEM } & \multicolumn{2}{|c|}{ CENTRO DE SAODE } \\
\hline & $N^{\circ}$ & $\xi$ & $N^{\circ}$ & : \\
\hline$S I M$ & 14 & 14,1 & 23 & 29,9 \\
\hline$N \pi 0$ & 82 & 82,9 & 51 & 66,2 \\
\hline RESPOSTA & 3 & 3,0 & 3 & 3,9 \\
\hline$T \circ T A L$ & 99 & 100,0 & 77 & 100,0 \\
\hline
\end{tabular}

TABELA V

Participação das enfermeiras respondentes ao ensino de Enfermagem no que se refere à tuberculose em 1975 e/ou 1976

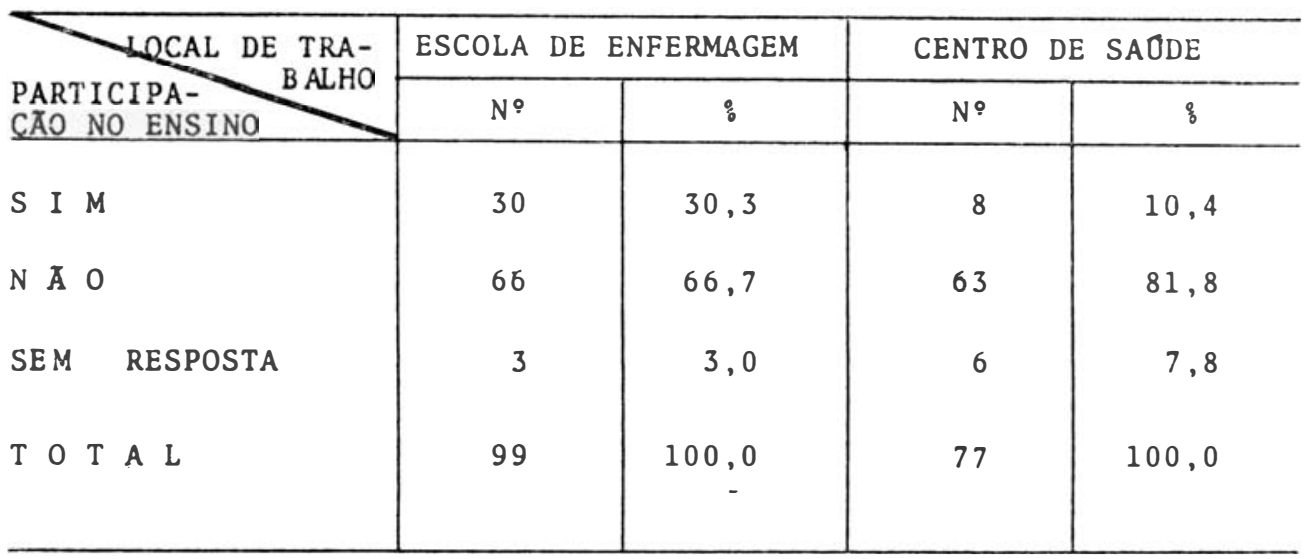


CASTRO, I.B. e Colaboradores - O ensino e a prática da enfermagem em relação å programa de controle da tuberculose no Estado do Rio de Janeiro. Rev. Bras. Ene.; DF, 33 : 318-355, 1980.

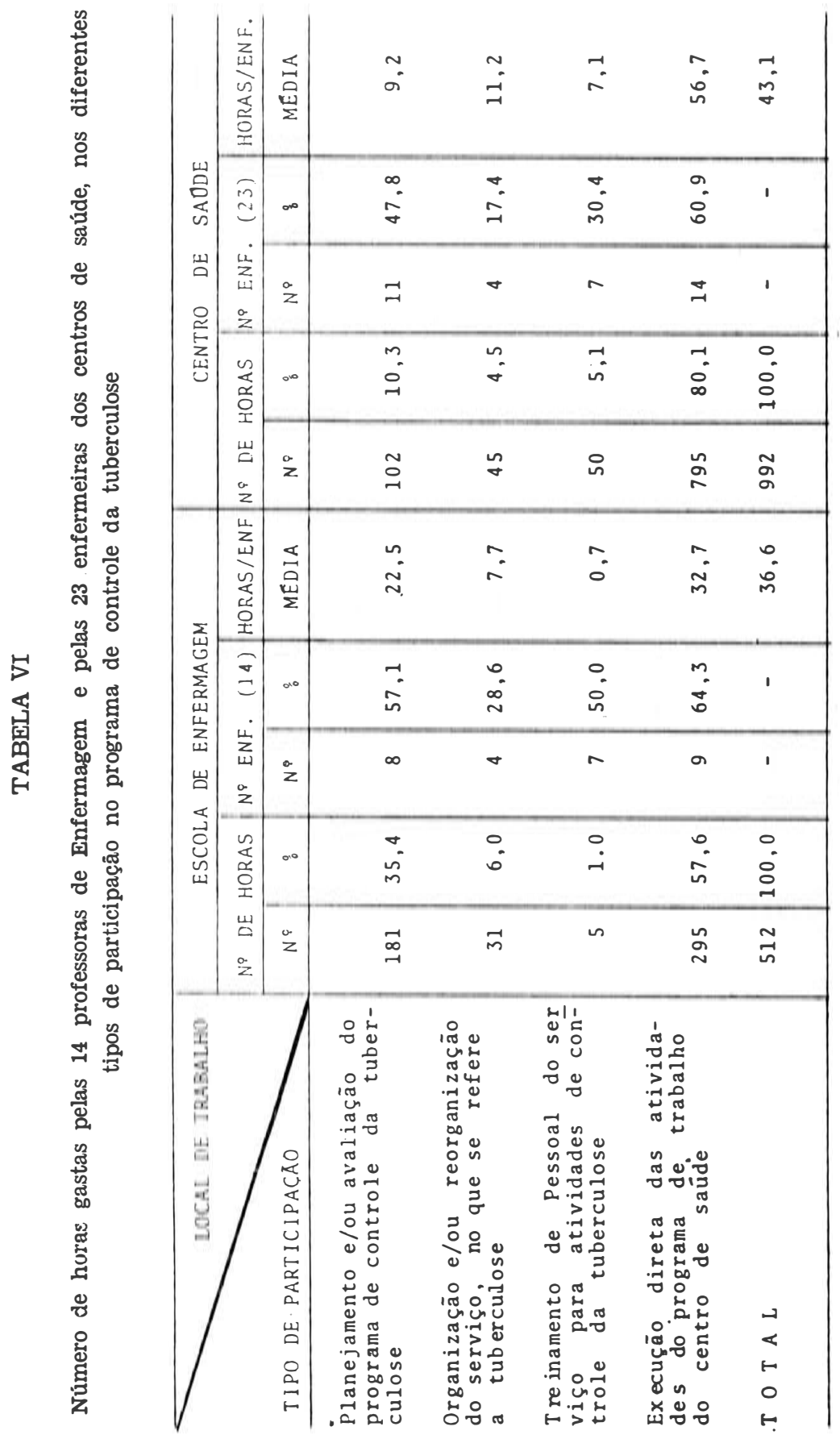


CASTRO, I.B. e Colaboradores - O ensino e a prática da enfermagem em relação ao programa de controle da tuberculose no Estado do Rio de Janeiro. Rev. Bras. Enf.; DF, 33 : 318-355, 1980.

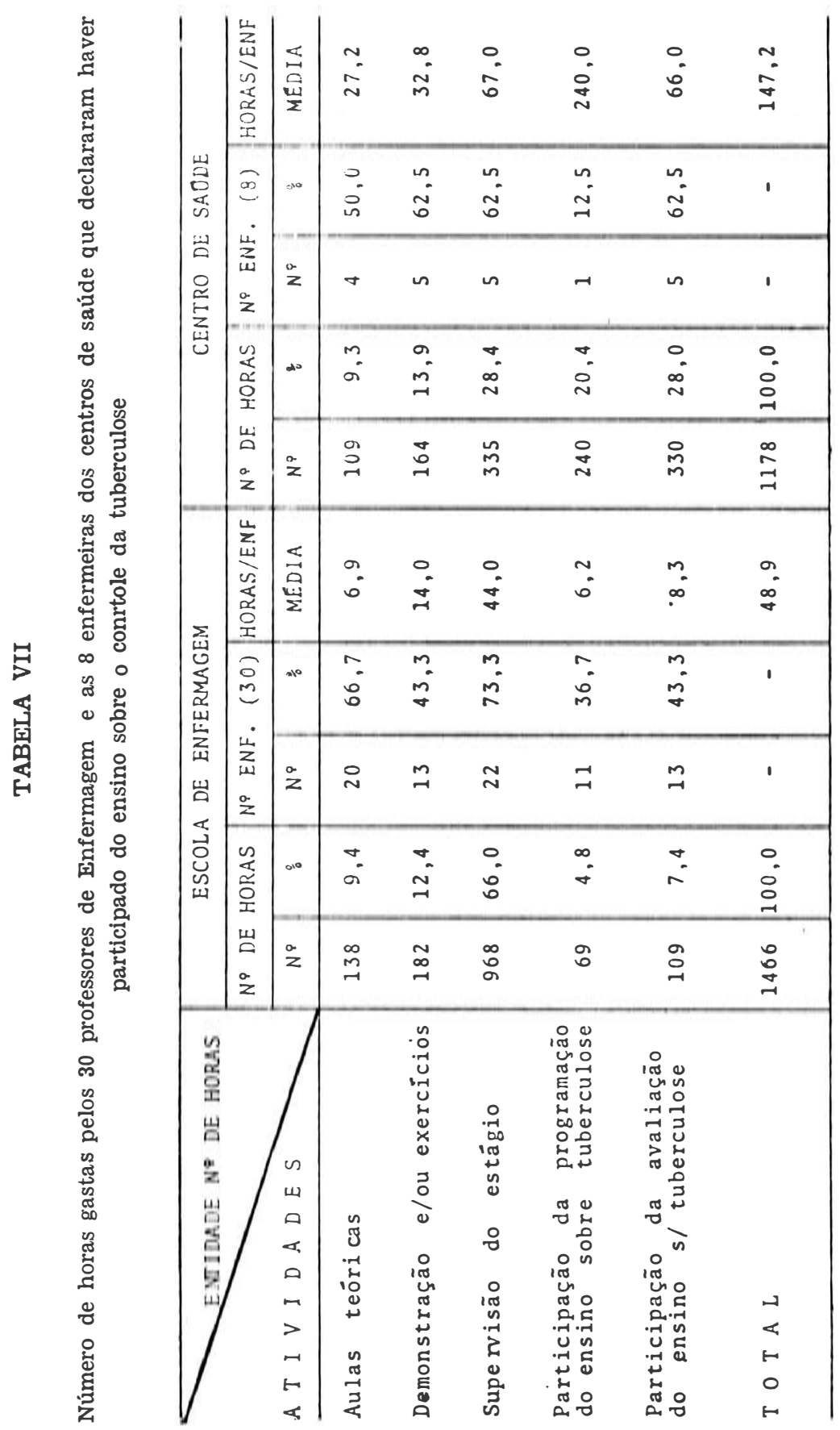


CASTRO, I.B. e Colaboradores - O ensino e a prática da enfermagem em relação ao programa de controle da tuberculose no Estado do Rio de Janeiro. Rev. Bras. Enf.: DF, 33 : 318-355, 1980.

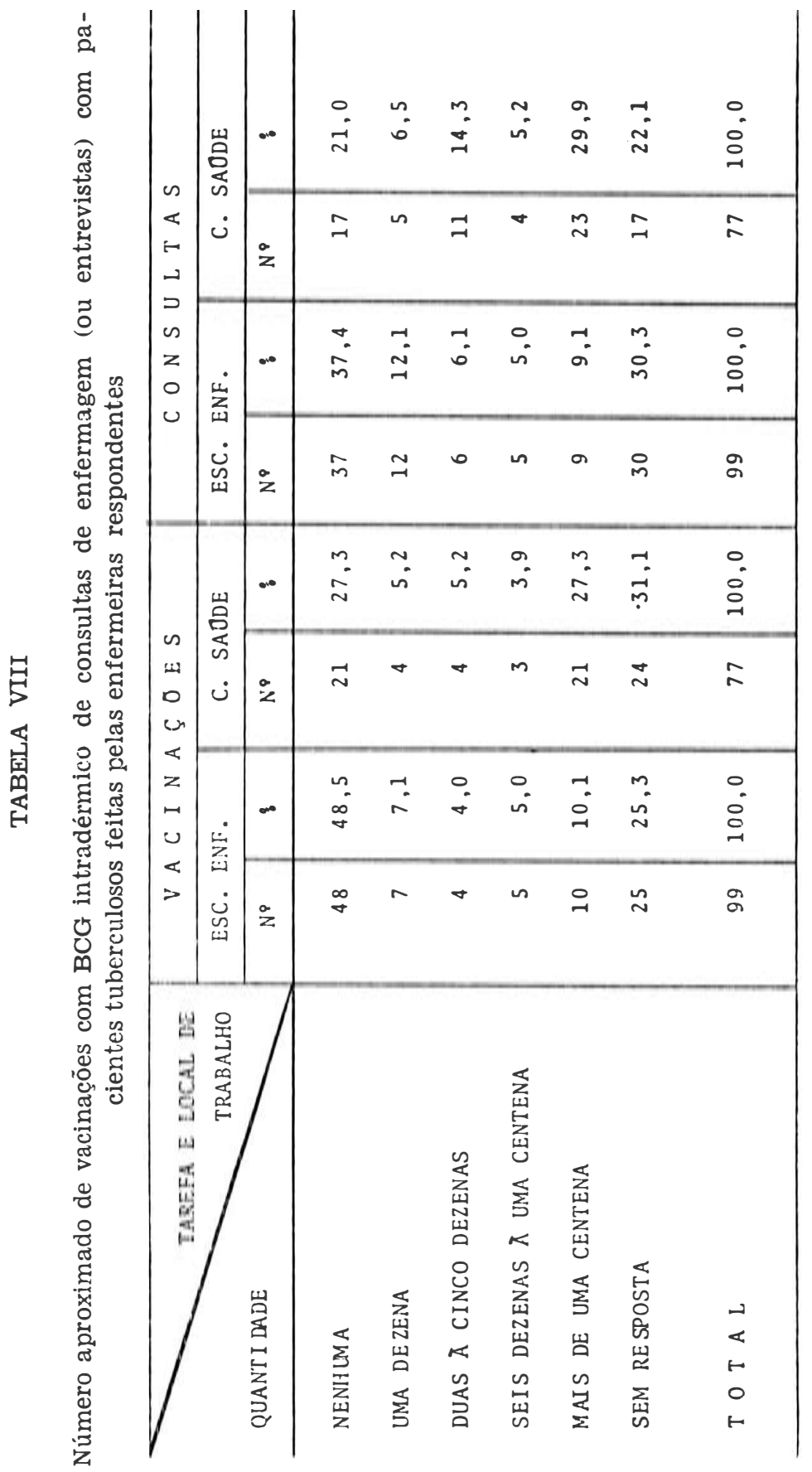


CASTRO, I.B. e Colaboradores - O ensino e a prática da enfermagem em relação ao programa de controle da tuberculose no Estado do Rio de Janeiro. Rev. Bras. Enf.: DF, 33 : 318-355, 1980.

TABELA IX

Opinião das enfermeiras quanto a sentirem-se preparadas para desenvolver outras atividades relacionadas à tuberculose, além das que já desenvolvem no momento

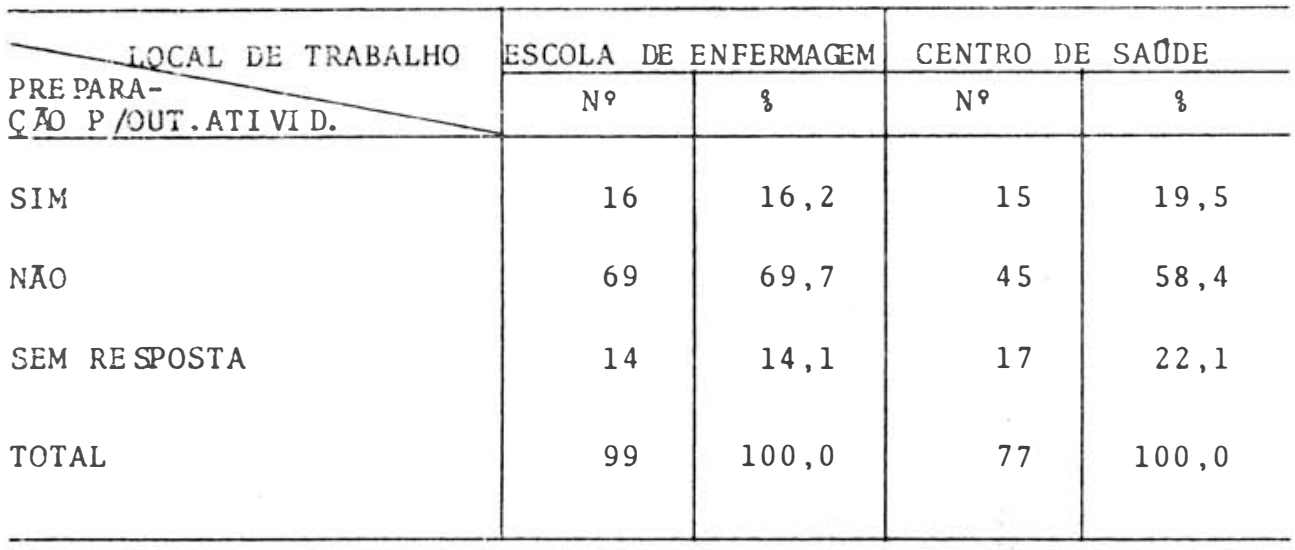

TABELA X

Opiniāo das 16 professoras e das 15 enfermeiras de centro de saúde sobre as atividades relacionados à tuberculose que poderiam desenvolver, além das que já desenvolvem no momento

\begin{tabular}{|c|c|c|c|c|}
\hline \multirow[b]{2}{*}{ ATIVIDADES } & \multicolumn{2}{|c|}{ ESCOLA DE ENFERMAGEM } & \multicolumn{2}{|c|}{ CENTRO DE SAÚDE } \\
\hline & $\mathrm{N}^{\circ}$ & $\xi$ & N.9 & $\xi$ \\
\hline $\begin{array}{l}\text { Toda e qualquer atividade em } \\
\text { tuberculose }\end{array}$ & 5 & 31,5 & 11 & 73,3 \\
\hline Educaçāo para a saúde & 5 & 31,2 & 2 & 13,3 \\
\hline $\begin{array}{l}\text { Programa BCG intradérmico e/ou } \\
\text { PPD }\end{array}$ & 3 & 18,7 & 3 & 20,0 \\
\hline $\begin{array}{l}\text { Descoberta de casos e/ou contro- } \\
\text { le de comunicantes }\end{array}$ & 2 & 12,4 & 2 & 13,3 \\
\hline $\begin{array}{l}\text { Entrevista com pacientes e/ou } \\
\text { controle de tratamento }\end{array}$ & 3 & 18,7 & 1 & 6,6 \\
\hline Pesquisa & 2 & 12,5 & - & - \\
\hline Sem resposta & - & - & 2 & 13,3 \\
\hline
\end{tabular}


CASTRO, I.B. e Colaboradores - O ensino e a prática da enfermagem em relação ao programa de controle da tuberculose no Estado do Rio de Janeiro. Rev. Bras. Enf.; DF, 33 : 318-355, 1980.

\section{TABELA XI}

Opinião das enfermeiras respondentes sobre que orientação daria a um doente recém-diagnosticado quanto aos seus hábitos de vida

\begin{tabular}{|c|c|c|c|c|}
\hline \multirow{2}{*}{ HÅBITOS } & \multicolumn{2}{|c|}{ ESCOLA DE ENFERMAGEM } & \multicolumn{2}{|c|}{ CENTRO DE SAODE } \\
\hline & $\mathrm{N}^{9}$ & $\xi$ & $N^{\circ}$ & $\because$ \\
\hline \multicolumn{5}{|l|}{ ALIMENTAÇÃO } \\
\hline - Super alimentação & 52 & 52,5 & 36 & 46,8 \\
\hline - Alimentaçāo habitual & 37 & 37,4 & 41 & 53,2 \\
\hline - Sem resposta & 10 & 10,1 & - & - \\
\hline $\mathrm{T} O \mathrm{~T} A \mathrm{~L}$ & 99 & 100,0 & 77 & 100,0 \\
\hline \multicolumn{5}{|l|}{ ATIVIDADE FISICA } \\
\hline - Repouso & 55 & 55,6 & 50 & 64,9 \\
\hline - Atividade habitual & 33 & 33,3 & 26 & 33,8 \\
\hline - Sem resposta & 11 & 11,1 & 1 & 1,3 \\
\hline $\mathrm{T} O \mathrm{O} A \mathrm{~A}$ & 99 & 100,0 & 77 & 100,0 \\
\hline \multicolumn{5}{|l|}{ HIGIENE } \\
\hline - Separação de utensílios & 73 & 73,7 & 59 & 76.6 \\
\hline - Utensílios comuns & 17 & 17,2 & 18 & 23,4 \\
\hline - Sem resposta & 9 & 9,1 & - & - \\
\hline $\mathrm{T} O \mathrm{~T} A \mathrm{~L}$ & 99 & 100,0 & 77 & 100,0 \\
\hline DORMIDA & & & & \\
\hline - Separada & 83 & 83,8 & 55 & 71,4 \\
\hline - Comum & 6 & 6,1 & - & - \\
\hline - Sem resposta & 10 & 10,1 & 22 & 28,6 \\
\hline $\mathrm{T} O \mathrm{~T} A \mathrm{~L}$ & 99 & 100,0 & 77 & 100,0 \\
\hline
\end{tabular}


CASTRO, I.B. e Colaboradores - O ensino e a prática da enfermagem em relação ao programa de controle da tuberculose no Estado do Rio de Janeiro. Rev. Bras. Enf.; DF, 33 : 318-355, 1980.

\section{TABELA XII}

Opiniāo das enfermeiras sobre que setores devem desenvolver as atividades do programa de controle da tuberculose

\begin{tabular}{|c|c|c|c|c|}
\hline \multirow[t]{2}{*}{ LOCAL DE TRABALHO } & \multicolumn{2}{|c|}{ ESC. ENF. } & \multicolumn{2}{|c|}{ C.SAUDE } \\
\hline & $N^{\bullet}$ & : & $\mathrm{N}^{P}$ & $:$ \\
\hline $\begin{array}{l}\text { Por todos os setores do Centro de } \\
\text { Saúde (materno-infantil, doenças } \\
\text { transmissíveis agudas, ect.) }\end{array}$ & 53 & 53,6 & 27 & 35,1 \\
\hline Pelos Dispensários de Tuberculose & 14 & 14,1 & $2 s$ & 37.6 \\
\hline Ambas as respostas acima & 23 & 23,2 & 16 & 20,8 \\
\hline Sem resposta & 9 & 9,1 & 5 & 6,5 \\
\hline TO $O A$ A & 99 & 100,0 & 77 & 100,0 \\
\hline
\end{tabular}

TABELA XIII

Opinião das enfermeiras sobre a possibilidade de tratar o paciente tuberculoso acometido de outro problema de saúde, em hospital geral

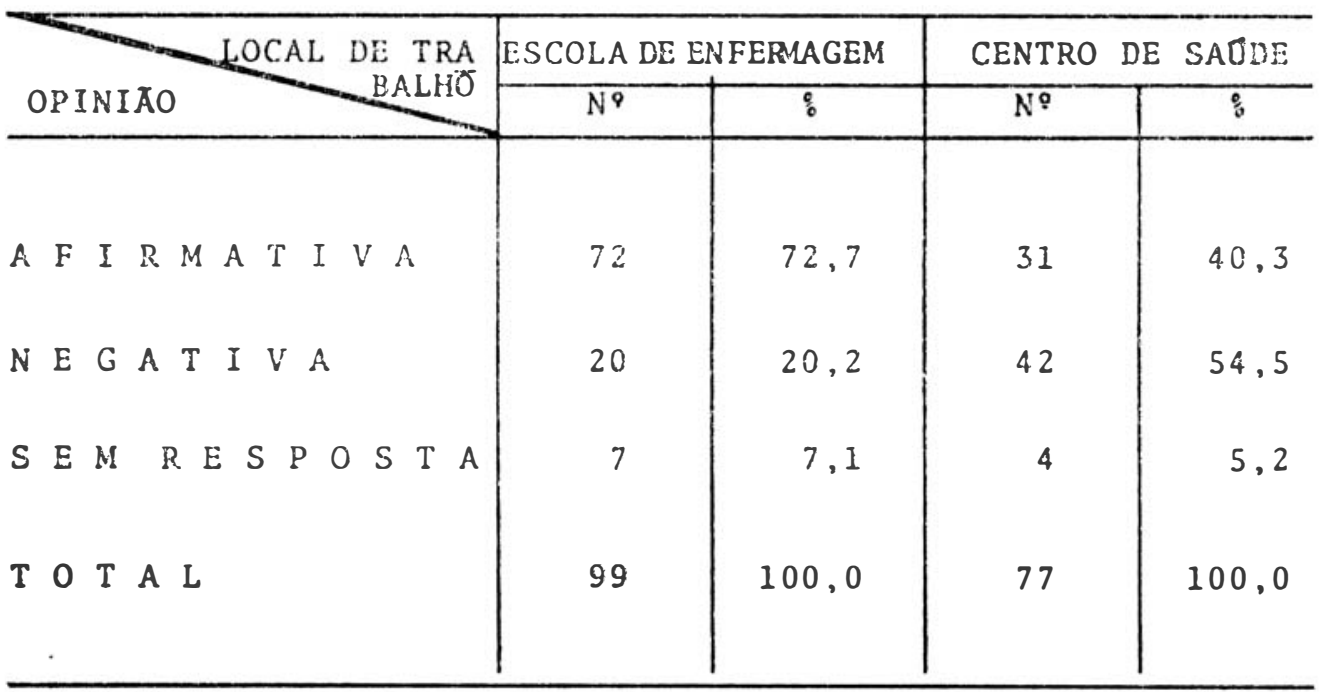


CASTRO, I.B. e Colaboradores - O ensino e a prática da enfermagem em relação ao programa de controle da tuberculose no Estado do Rio de Janeiro. Rev. Bras. Enf.; DF, 33 : 318-355, 1980.

TABELA XIV

Razões apontadas pelas 72 enfermeiras da área de ensino e 31 da área assistencial para que os doentes de tuberculose sejam internados em hospitais gerais

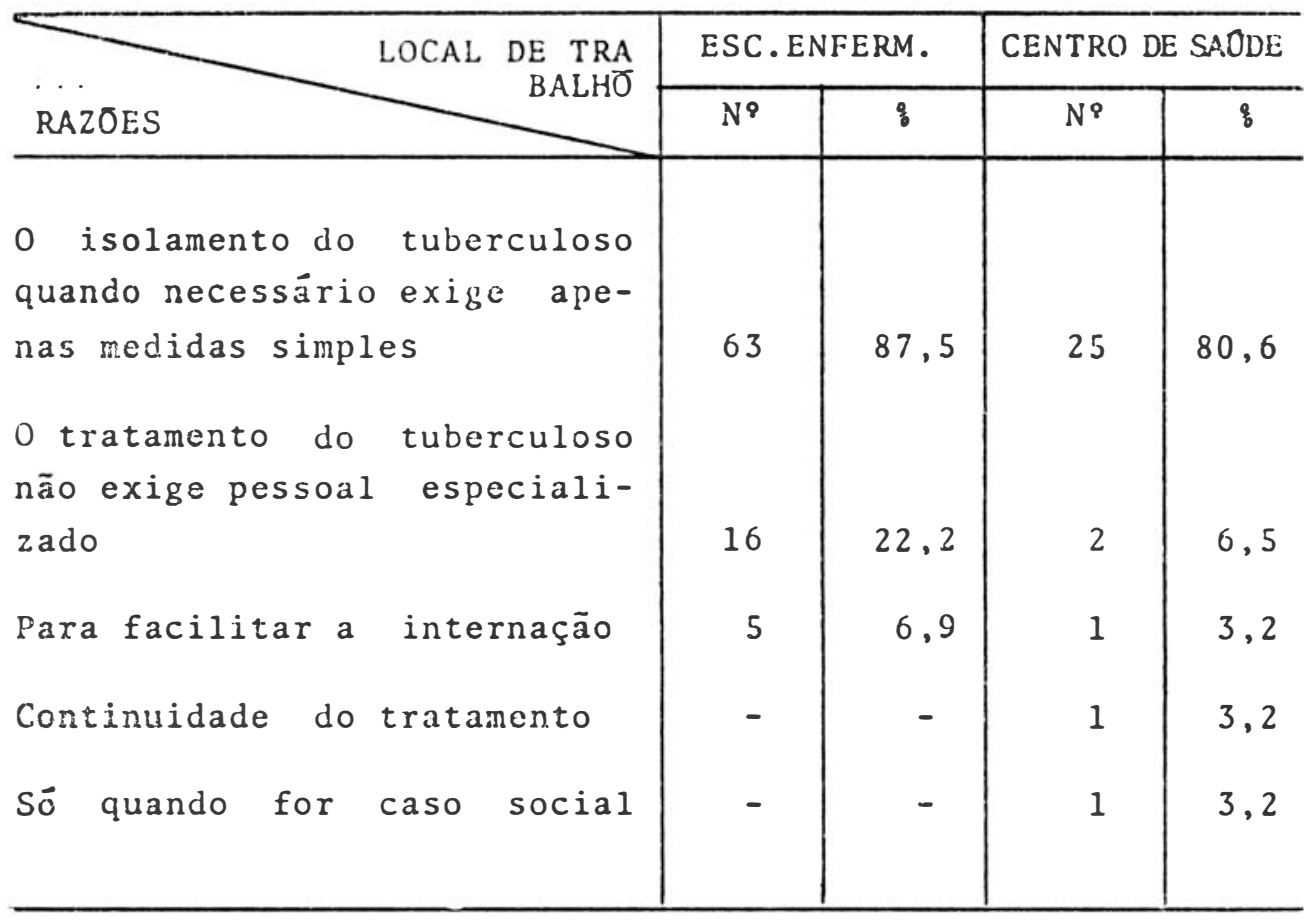


CASTRO, I.B. e Colaboradores - O ensino e a prática da enfermagem em relação ao programa de controle da tuberculose no Estado do Rio de Janeiro. Rev. Bras. Ent.; DF, 33 : 318-355, 1980.

TABELA XV

Opiniāo das 20 enfermeiras de escolas e de 42 de centros de saúde sobre a impossibllidade de tratar o paciente tuberculoso acometido de outro problema de saúde

\begin{tabular}{|c|c|c|c|c|}
\hline \multirow[b]{2}{*}{ OPINIAO } & \multicolumn{2}{|c|}{ ESC. ENFERM. } & \multicolumn{2}{|c|}{ CENTRO SAONE } \\
\hline & $\mathrm{N}^{\circ}$ & $q \cdot$ & $N^{8}$ & $q$ \\
\hline 0 tratamento da tuberculose & & & & \\
\hline pode ficar prejudicado & 10 & 50,00 & 34 & 81,0 \\
\hline E perigoso para os outros & & & & \\
\hline pacientes & 15 & 75,0 & 31 & 73,8 \\
\hline E. perigoso para a equipe do & & & & \\
\hline Hospital & 3 & 15,0 & 24 & 57,1 \\
\hline Falta de preparo dos hospi- & & & & \\
\hline b erculoso & 2 & 10,0 & - & - \\
\hline
\end{tabular}


CASTRO, I.B. e Colaboradores - O ensino e a prática da enfermagem em relação ao programa de controle da tuberculose no Estado do Rio de Janeiro. Rev. Bras. Enf.; DF, 33 : 318-355, 1980.

TABELA XVI

Opinião das enfermeiras sobre o que considera imprescindível a uma enfermeira recém-formada saber fazer para atuar em um programa de tuberculose

\begin{tabular}{|c|c|c|c|c|}
\hline \multirow[b]{2}{*}{ A TIVIDADES } & \multicolumn{2}{|c|}{ ESC. ENFERM. } & \multicolumn{2}{|c|}{ C. SAUDE } \\
\hline & $\mathrm{N}^{8}$ & $\because$ & $N^{2}$ & $\because$ \\
\hline $\begin{array}{l}\text { Ap licação de prova tuberculínica } \\
\text { e/ou BCG }\end{array}$ & 45 & 45,5 & 74 & 96,1 \\
\hline $\begin{array}{l}\text { Leitura padronizada de provas tu } \\
\text { berculinicas }\end{array}$ & 42 & 42,4 & 74 & 96,1 \\
\hline $\begin{array}{l}\text { Consulta de Enfermagem ao Tuber- } \\
\text { culoso }\end{array}$ & 46 & 46,5 & 66 & 85,7 \\
\hline $\begin{array}{l}\text { Visita domiciliāria a famílias } \\
\text { c/ caso de tuberculose }\end{array}$ & 41 & 41,4 & 66 & 85,7 \\
\hline $\begin{array}{l}\text { Aprazamento e controle do compa- } \\
\text { recimento dos doentes }\end{array}$ & 40 & 40,4 & 69 & 89,6 \\
\hline $\begin{array}{l}\text { Palestras educativas sobre tu- } \\
\text { berculose }\end{array}$ & 40 & 40,4 & 63 & 81,8 \\
\hline $\begin{array}{l}\text { Preparação e lâmina e/ou micros } \\
\text { copia }\end{array}$ & 7 & 7,1 & 8 & 10,4 \\
\hline Adminis tração e supervisão & - & - & 39 & 50,6 \\
\hline $\begin{array}{l}\text { Calcular objeticos quantitativos, } \\
\text { cobertura alcançada etc. }\end{array}$ & 24 & 24,2 & 30 & $+39,0$ \\
\hline Orientação de grupos & 1 & 1,0 & - & - \\
\hline Levantamento de dados & 1 & 1,0 & - & - \\
\hline
\end{tabular}


CASTRO, I.B. e Colaboradores - O ensino e a prática da enfermagem em relaçāo an programa de controle da luberculose no Estado do Rio de Janeiro. Rev. Bras. Enf.; DF, 33 : 318-355, 1980.

\section{TABELA XVII}

Opinião das enfermeiras sobre que dificuldades teria que superar uma enfermeira não especializada para prestar assistência a pacientes tuberculosos e suas famílias

\begin{tabular}{|c|c|c|c|c|}
\hline \multirow{2}{*}{ DIFICULDADES } & \multicolumn{2}{|c|}{ ESC. ENFERM. } & \multicolumn{2}{|c|}{ C. SAODE } \\
\hline & $\mathrm{N}^{9}$ & $\delta$ & $\mathrm{N}^{9}$ & 3 \\
\hline $\begin{array}{l}\text { De sconhecimento das normas de } \\
\text { controle da tuberculose }\end{array}$ & 56 & 56,6 & 63 & 81,8 \\
\hline $\begin{array}{l}\text { Dúvida quanto ao modo de proce- } \\
\text { der para evitar o contágio }\end{array}$ & 26 & 26,3 & 40 & 51,9 \\
\hline $\begin{array}{l}\text { Dúvida quanto ao modo de desen- } \\
\text { volver a consulta ou entrevis- } \\
\text { ta de enfermagem }\end{array}$ & 41 & 41,4 & 55 & 71,4 \\
\hline $\begin{array}{l}\text { Düvida quanto a orientação da } \\
\text { familia do paciente }\end{array}$ & 43 & 43,4 & 50 & 64,9 \\
\hline $\begin{array}{l}\text { Falta de destreza para a rea- } \\
\text { lização da prova tuberculínica }\end{array}$ & 45 & 45,5 & 58 & 75,3 \\
\hline $\begin{array}{l}\text { Falta de destreza para a apli- } \\
\text { cação da vacina BCG intradér- } \\
\text { mica }\end{array}$ & 42 & 42,4 & 60 & 77,9 \\
\hline $\begin{array}{l}\text { Como encaminhar a serviço espe } \\
\text { cializado }\end{array}$ & 1 & 1,0 & - & - \\
\hline Falta de atualizaçāo & 1 & 1,0 & 1 & 1,3 \\
\hline resposta & - & - & 2 & 2,6 \\
\hline
\end{tabular}


CASTRO, I.B. e Colaboradores - O ensino e a prática da enfermagem em relação ao programa de controlt da tuberculose no Estado do Rio de Janeiro. Rev. Bras. Enf.; DF, 33 : 318-355 $19\{0$.

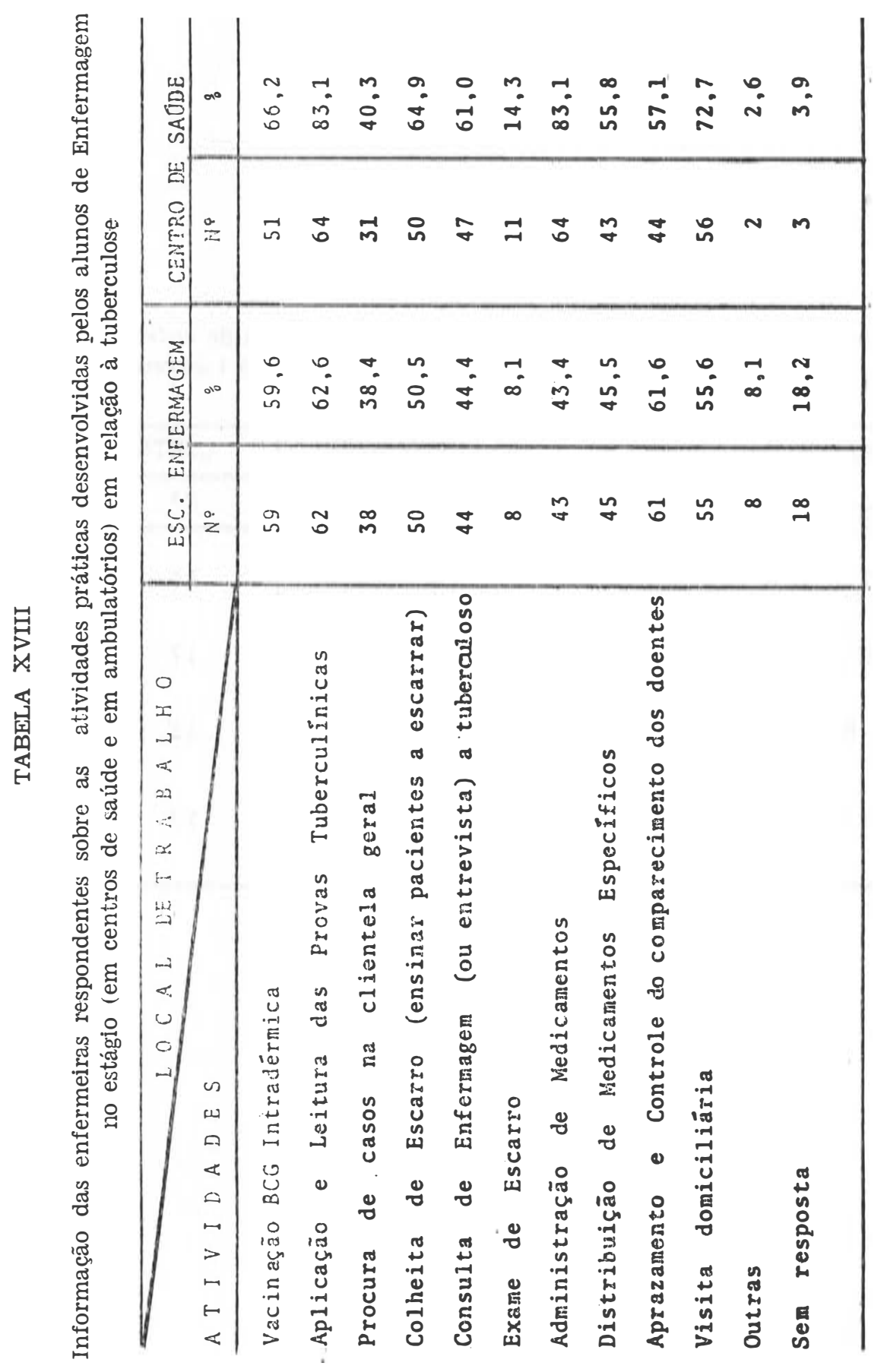


CASTRO, I.B. e Colaboradores - O ensino e a prática da enfermagem em relação ao programa de controle da tuberculose no Estado do Rio de Janeiro. Rev. Bras. Enf.; DF, 33 : 318-355, 1980.

TABELA XIX

Opinião das enfermeiras sobre a necessidade de as escolas de enfermagem modificarem o preparo dos seus alunos em relação à tuberculose

\begin{tabular}{l|c|c|c|c}
\hline & LOCAL DE TRA- & \multicolumn{2}{|c|}{ ESC.ENFERMAGEM } & \multicolumn{2}{c}{ CENTRO DE SAODE } \\
\cline { 2 - 6 } OPINIAO & $\mathrm{N} \%$ & $\ddots$ & $\mathrm{N} \%$ & $\%$ \\
\hline A F I R M A T I V A & 73 & 73,7 & 45 & 58,4 \\
N E G A T I V A & 10 & 10,1 & 17 & 22,1 \\
SEM RESPOSTA & 16 & 16,2 & 15 & 19,5 \\
T O T A L & 99 & 100,0 & 77 & 100,0 \\
\hline
\end{tabular}


CASTRO, I.B. e Colaboradores - O ensino e a prática da enfermagem em relação ao programa de controle da tuberculose no Estado do Rio de Janeiro. Rev. Bras. Enf.; DF, 33 : 318-355, 1980.

TABELA XX

Opinião das enfermeiras sobre as modificações recomendáveis no preparo dos alunos em relação à tuberculose

\begin{tabular}{|c|c|c|c|c|}
\hline \multirow[b]{2}{*}{ MODIFICAÇ,OES } & \multicolumn{2}{|c|}{ ESC. ENFERMAGEM } & \multirow{2}{*}{$\frac{\text { CENTR }}{N^{\circ}}$} & \multirow{2}{*}{$\frac{\text { SAGDE }}{\because}$} \\
\hline & $N^{9}$ & $\because$ & & \\
\hline $\begin{array}{l}\text { Enfatizar o ensino sobre tuberculo } \\
\text { se nas disciplinas básicas (Bacte- } \\
\text { riologia, Imunologia, Epidemiolo- } \\
\text { gia, etc.) }\end{array}$ & 55 & 55,6 & 27 & 35,1 \\
\hline $\begin{array}{l}\text { Reforçar o ensino sobre Diagnósti- } \\
\text { co e Tratamento de Tuberculose }\end{array}$ & 55 & 55,6 & 23 & 29.9 \\
\hline $\begin{array}{l}\text { Des envolver malor habilidade técri } \\
\text { ca (PPD, BCG, etc.) }\end{array}$ & 47 & 47,4 & 36 & 46,8 \\
\hline $\begin{array}{l}\text { Desenvolver maior habilidade para } \\
\text { consultas de enfermagem e visitas } \\
\text { domiciliares ao paciente tubercu- } \\
\text { loso }\end{array}$ & 55 & 55,6 & 38 & 49,4 \\
\hline $\begin{array}{l}\text { Desenvolver maior habilidade admi } \\
\text { nistrativa }\end{array}$ & 18 & 18,2 & 21 & 27,3 \\
\hline $\begin{array}{l}\text { Incentivar o entusiasmo em relação } \\
\text { aos programas de controle da tu- } \\
\text { be rculose }\end{array}$ & 56 & 56,6 & 39 & 50,6 \\
\hline Outros & 4 & 4,0 & 5 & 6,5 \\
\hline
\end{tabular}




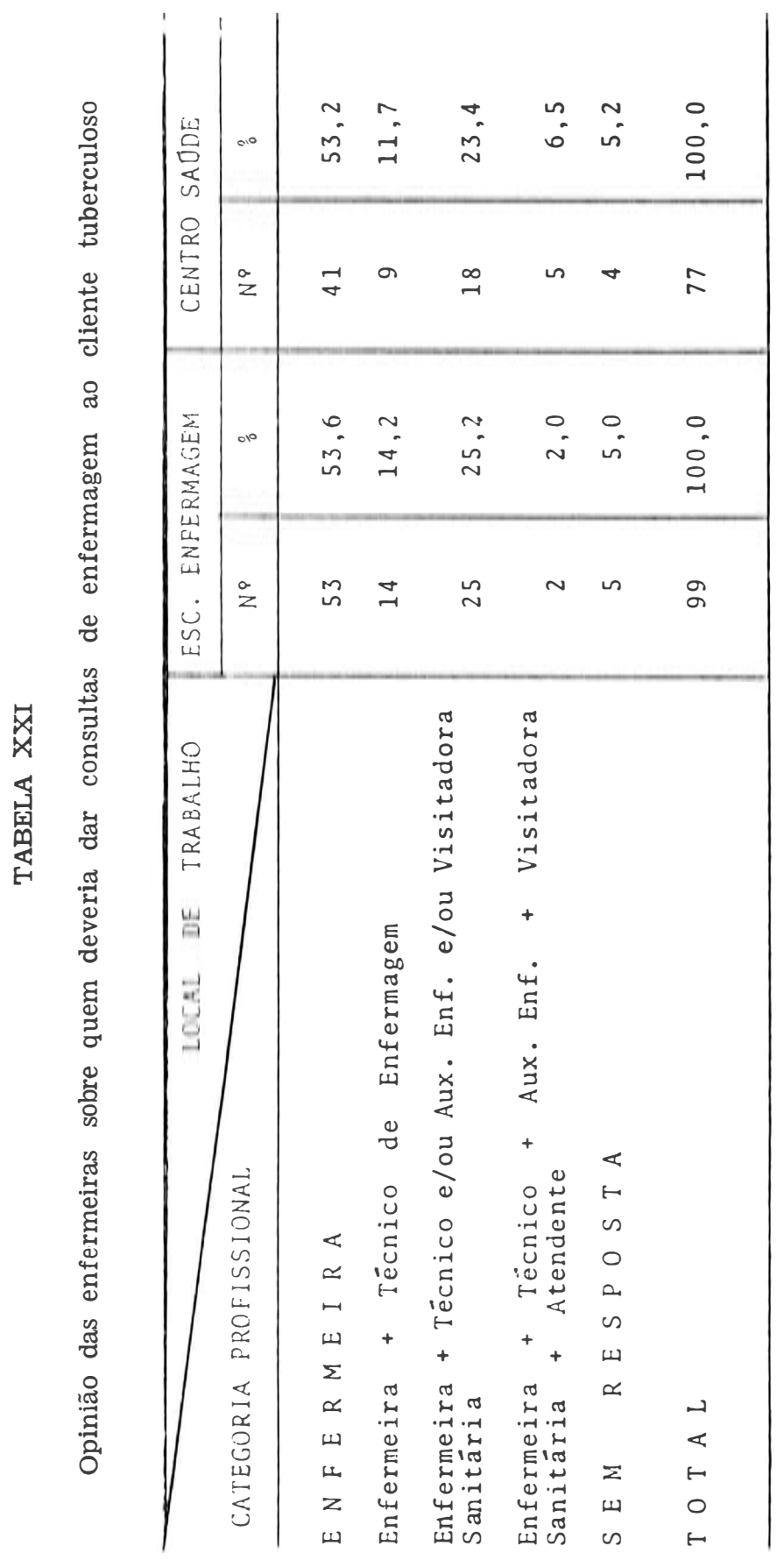


CASTRO, I.B. e Colaboradores - O ensino e a prática da enfermagem em relação ao programa de controle da tuberculose no Estado do Rio de Janeiro. Rev. Bras. Enp.; DF, 33 : 318-355, 1980.

\section{B I B L I O G R A F I A}

CASTRO, Ieda Barreira e Encuestta sobre la enseñanza de la tuberculosis en las escuelas de enfermeria de America Latina. Informe de Enfermeria n. 21. Washington, D.C., OPS/OMS, 1976.

A formtção de profissionais de enfermagem e os programas de controle da tuberculose. Tese de Livredocência apresentada à Escola de Enfermagem Ana Neri da Universidade Federal do Rio de Janeiro, 1976.

Adiestramiento del personal auxiliar de enfermeria para programas integrados de control de tuberculosis. In: - - Manual de Normas e Procedimentos para programas integrados de control de tuberculosis en America
Latina. Washington, D.C., 1977. Anexo I.

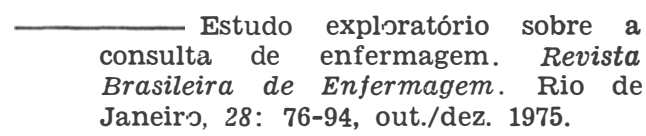

DIVISÃO NACIONAL DE PNEUMOLOGIA SANITARIA. Divisão Nac. Pneumol. Sanit. Manual de Normas para o controle da tuberculose. Rio de Janeiro, 1979 .

DIVISÃO NACIONAL DE PNEUMOLOGIA SANITARIA. Divisão Nac. Pneumol. Sanit. Manual de procedimentos para unidades de saúde. Rio de Janeiro, 1979.

\section{ANEXO I}

\section{DIVISÃO NACIONAL DE TUBERCULOSE}

\section{PESQUISA SOBRE O ENSINO E A PRATICA DA ENFERMAGEM EM RELAÇÃO AOS PROGRAMAS DE CONTROLE DA TUBERCULOSE}

\section{INSTRUÇÕES PARA O PREENCHIMENTO DO QUESTIONARIO}

1. Este questionário não tem a finalidade de testar conhecimentos. Ele não será computado em termos individuais. Ele pretende apenas fornecer uma idéia da experiência de um grupo de enfermeiras, em relação à tuberculose, e sua opinião sobre alguns problemas do ensino e da prática de enfermagem a ela relacionados.

2. Existem questões de vários tipos, portanto, antes de responder, assegurese que entendeu bem as instruções para cada tipo de pergunta.

3. Depois de preenchido, os questionários deverão ser reunidos na Chefia do Departamento de Enfermagem, onde serão recolhidos pela Coordenação da Pesquisa.

4. A Coordenadora de Pesquisa, Ieda Barreira e Castro, enfermeira da Divisão Nacional de Tuberculose (tel.: 2-522282) e professora do Departamento de Enfermagem de Saúde Pública da Escola Ana Neri (tel.: 2-249351) colocase à disposição das colegas para quaisquer esclarecimentos que se façam necessários e desde já agradece sua decisiva colaboração, representada pelo preenchimento dos questionários. 
CASTRO, I.B. e Colaboradores - O ensino e a prática da enfermagem em relação ao programa de controle da tuberculose no Estado do Rio de Janeiro. Rev. Bras. Enf.; DF, 33 : 318-355, 1980.

\section{DIVISÃO NACIONAL DE TUBERCULOSE}

PESQUISA SOBRE O ENSINO E A PRÁTICA DE ENFERMAGEM EM RELAÇÃO AOS PROGRAMAS DE CONTROLE DA TUBERCULOSE

1. Local de trabalho

Nome da instituição:

Departamento, Serviço ou Setor onde trabalha:

2. Em que Escola de Enfermagem se formou? (escreva o nome da Escola e da instituição a que ela percente)

Cidade:

Estado:

Ano da formatura:

3. Depois que concluiu o Curso de Enfermagem, de que cursos e/ou treinamentos já participou, nos quais tenha aprendido algo sobre o controle da tuberculose?

Nome do curso

Ano em que cursou

4. Em que tipos de instituição trabalhou ou trabalha de 1970 para cá?

Escola de Enfermagem

Centro de Saúde

Hospital Geral

Ambulatório isolado

Hospital especializado

qual especialidade? 
CASTRO, I.B. e Colaboradores - O ensino e a prática da enfermagem em relação so prngrama de controle da tuberculose no Estado do Rio de Janeiro. Rev. Bras. Enf.; DF, 33 : 318-355, 1980.

7. Em 1975 ou 1976 participou do ensino de alunos de enfermagem, no que se refere à tuberculose?

\section{SIM}

NÃO

Se respondeu SIM, anote ao lado de cada atividade o número de horas gastas.
Atividades
N.o de
horas
- aulas teóricas
— demonstrações e/ou exercícios
— supervisão de estágio
- participou da programação do ensino sobre tuberculose
- participou da avaliação do en-
sino sobre tuberculose

8. Sente-se preparada para desenvolver outras atividades relacionadas à tuberculose, além das que já desenvolve no momento?

SIM

$\square$ - quais?

NÃO

9. Quantas vacinações com o BCG intradérmico e quantas consultas de enfermagem (ou entrevistas) com pacientes tuberculosos já teve a oportunidade de fazei, aproximadamente?

\section{Vacina intradérmica}

Consulta enfermagem

Nenhuma

Uma dezena

Duas a cinco dezenas

Seis dezenas a uma centena

Mais de uma centena

10. Que orientação daria a um doente tuberculoso recém-diagnosticado, quanto à:

- alimentação superalimentação

alimentação habitual 
CASTRO, I.B. e Colaboradores - O ensino e a prática da enfermagem em relaçäo ao programa de controle da tuberculose no Estado do Rio de Janeiro. Rev. Bras. Enf.: DF, 33 : 318-355, 1980.

5. Nas instituições onde trabalha há normas e rotinas escritas sobre o controle da tuberculose?

a) Nome da instituição

\section{SIM}

NÃO

b) Nome da instituição

SIM

NÃO

6. Em 1975 ou 1976 participou do programa de controle da tuberculose da cidade?

SIM

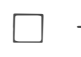

$$
\text { — em que instituição? }
$$

$\ldots \ldots$

NÃO

Se respondeu SIM, anote ao lado de cada

atividade o número de horas gastas.

Atividades

- planejamento e/ou avaliação do

programa de controle da tuber-

culose

- organização e/ou reorganização

do serviço, no que se refere à

tuberculose

- treinamento do pessoal do serviço para atividades de controle da tuberculose

- execução direta de atividade do programa de trabalho do serviço
N.o de

horas
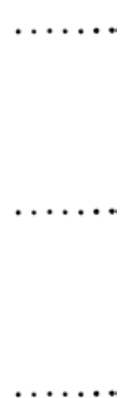

$\ldots \ldots \ldots-$ quais atividades? ...... 
CASTRO, I.B. e Colaboradores - O ensino e a prática da enfermagem em relação ao programa de controle da tuberculose no Estado do Rio de Janeiro. Rev. Bras. Enᄃ.: DF, 33 : 318-355, 1980.

- atividade física

- higiene

- dormida
- repouso

- atividade habitual

- separação de utensílios

- utensílios comuns

- separada

- comum

12. Considera que as atividades do programa de controle da tuberculose devem ser desenvolvidas:

- por todos os setores da unidade sanitária (materno-infantil, doenças transmissíveis agudas, etc.)

- pelos disponsários de tuberculose

13. Considera que o paciente tuberculoso, acometido de outro problema de saúde, deve ser tratado em hospital geral?

SIM $\square-$ por quê? - o isolamento do tuberculoso, quando é necessário, exige apenas medidas simples

- o tratamento da tuberculose não exige pessoal especializado

- para facilitar a internação de tuberculosos

- outra razão - qual?

NĀO $\square$ - por quê? - o tratamento de tuberculose pode ficar prejudicado

- é perigoso para os outros pacientes

- é perigoso para a equipe do hospital

- outra razão - qual?

14. O que considera imprescindível a uma enfermeira recém-formada saber para atuar em um programa de controle de tuberculose?

- aplicação da prova tuberculínica e/ou vacinação BCG

- leitura padronizada de provas tuberculínicas

- consulta de enfermagem ao tuberculoso

- visita domiciliária a famílias c/casos de tuberculose 
CASTRO, I.B. e Colaboradores - O ensino e a prática da enfermagem em relação ao prigrama de controle da tuberculose no Estado do Rio de Janeiro. Rev. Bras. Enf.; DF, 33 : 318-355, 1980.

- aprazamento e controle do comparecimento dos doentes

- efetuar palestras educativas sobre tuberculose

- preparação da lâmina e/ou microscopia

- administração e supervisão

- calcular objetivos quantitativos, cobertura alcançada, etc.

- outra - qual?

15. Que dificuldades teria que superar uma enfermeira não especializada no assunto para prestar assistência a pacientes tuberculosos e suas famílias?

- desconhecimento das normas de controle da tuberculose

— dúvida quanto ao modo de proceder para evitar o contágio

- dúvida quanto ao modo de desenvolver a consulta (ou entrevista) de enfermagem

- dúvida quanto à orientação da famíia do paciente

- falta de destreza para a realização da prova tuberculínica

- falta de destreza para a aplicação da vacina BCG intradérmica outra dificuldade - qual?

16. Que atividades práticas são desenvolvidas pelos alunos de enfermagem no estágio (em centros de saúde e em ambulatórios), em relação à tuberculose?

- vacinação BCG intradérmica

- aplicação e leitura de provas tuberculínicas

- procura de casos de tuberculose na clientela geral

- colheita de escarro (ensinar o paciente a escarrar)

- consulta de enfermagem (ou entrevista) a tuberculosos

- exames de escarro

- administração de medicamentos

- distribuição de medicamentos específicos

- aprazamento e controle do comparecimento dos doentes

- visitação domiciliária 
CASTRO, I.B. e Colaboradores - O ensino e a prática da enfermagem em relação ao programa de controle da tuberculose no Estado do Rio de Janeiro. Rev. Bras. Enf.; DF, $33: 318-355,1980$.

- outra - qual?

17. Julga que as Escolas de Enfermagem deveriam modificar o preparo dos alunos, em relação à tuberculose?

SIM

NÃO

Se respondeu SIM, assinale as modificaçōes recomendáveis:

- enfatizar o ensino sobre a tuberculose nas disciplinas básicas (bacteriologia, imunologia, epidemiologia, etc.)

- reforçar o ensino sobre diagnóstico e tratamento da tuberculose

- desenvolver maior habilidade técnica (PPD, BCG, etc.)

- desenvolver maior habilidade para consultas de enfermagem e visitas domiciliares ao paciente tuberculoso

- desenvolver maior habilidade administrativa

- incentivar o entusiasmo em relação aos programas de tuberculose

- outra alteração — qual?

18. Quem pode dar consulta de enfermagem ao paciente tuberculoso? (assinale os quadros que achar necessários)

enfermeira

técnico de enfermagem

auxiliar de enfermagem

visitadora sanitária

atendente 